\title{
Energy storage system design for large-scale solar PV in Malaysia: techno-economic analysis
}

\author{
Mahmoud Laajimi and Yun li Go ${ }^{*}$ (]
}

\begin{abstract}
Large-scale solar is a non-reversible trend in the energy mix of Malaysia. Due to the mismatch between the peak of solar energy generation and the peak demand, energy storage projects are essential and crucial to optimize the use of this renewable resource. Although the technical and environmental benefits of such transition have been examined, the profitability of energy storage systems combined with large-scale solar PV has not been studied in Malaysia. This project aims to determine the most profitable business model of power systems, in terms of PV installed capacity, and energy storage capacity, and power system components. A comparative study has been done to compare the economic outcomes from different types of projects, with different scales and multiple configurations of large-scale solar PV combined with energy storage. The lowest values of LCOE are guaranteed with energy storage output to LSS output ratio, $A=5 \%$. In this case, 30-MW projects have the cheapest electricity, equal to RM $0.2484 / \mathrm{kWh}$. On the other hand, increasing the energy storage output to LSS output ratio, $A$ to $60 \%$ results in the increase of LCOE, exceeding RM $0.47 / \mathrm{kWh}$. On the economical side, with a difference of $0.06 \mathrm{kWh} / \mathrm{m}^{2} /$ day for the analysis carried out in Pahang and Perak, the difference in net present worth is more than $7.5 \%$ of the net present cost. The difference between the two locations is comparatively higher for 50-MW projects. It is equal to RM 11.67 Million for $A=60 \%$, while it is equal to RM 13.5 Million with $A=5 \%$. Due to the energy prices in Malaysia, the projects that include large-scale solar only are more profitable technically and financially than those including large-scale solar and energy storage. It is found that adding storage to a large-scale solar project is more profitable technically and financially with greater large-scale solar capacities and smaller storage capacities. Nevertheless, with the current energy prices in Malaysia, projects that include only energy storage are not financially profitable. This study determined the parameters that affect the profitability of large-scale solar energy projects and energy storage projects, and the configurations that maximize financial profits. The findings of this study are useful for the future regulations that intend to enhance the deployment of largescale solar PV and energy storage in Malaysia.
\end{abstract}

Keywords: PV installed capacity, Energy storage, NPC, LCOE, ROI

\section{Introduction}

It has been the global goal for reduction of greenhouse gas emissions and steps to invest in renewable energy (RE) generation systems have been taken in many countries around the world. With the announced largescale solar projects, Malaysia is already on the way to reduce its greenhouse gas emissions. However, the

*Correspondence: y.go@hw.ac.uk

School of Engineering and Physical Sciences, Heriot-Watt University Malaysia, 1, Jalan Venna P5/2, Precinct 5, 62200 Putrajaya, Malaysia environmental outcome is not the only motivation for the authorities. Such projects must be financially profitable, in order to ensure their sustainability and to guarantee a future increase of the RE installed capacity after 2020 . Solar energy harvesting systems have been designed in many different forms and models. Each model varies in terms of how they operate and output capability, which in turn affects the profitability on industry. Implementation of the various models of solar and energy storage capacities often requires a multitude of aspects including geography, climate and demography of a region. The aspects 
mentioned can either give slight if not large impact to the financial income of solar power generation and storage. This study aims to compare different types of power systems that include large-scale solar and energy storage capacities, in order to determine the most profitable models. The comparative study is done in two different states in Malaysia-Pahang and Perak.

\section{PV storage systems}

Solar energy was present ever since the beginning of time and the form of energy that it was in is only the same. The only thing that changes over time is our understanding of how to harvest such abundance of energy efficiently with minimal wastage. PV harvesting in small scales have dated back since the 1950s and possibly earlier times within the nineteenth and twentieth century (Silvi 2008). The harvesting of solar energy was not done in large scale and not connected in a primary power grid until the 2009, where the first large-scale PV harvesting installation was installed. The $230 \mathrm{kV}$ utility scale PV system plant by Desoto Solar Energy Centre was established. Being the early plant to generate power for utility provision, the plant faces problems especially when compared to other types of renewable energy sources. One main problem for large-scale PV power storage and harvester is the uncontrollable amount of power generation and demand [shah2015]. It was from this root of problem that has led to many other researchers conduct plant feasibility and evaluations before considering establishment and integration of large-scale PV power plants.

\section{Energy storage systems design}

There are various system storage designs that are being tested for its feasibility in implementation as well as power generations. One of the energy storage design was developed by Babacan et al. (2017). This storage system design implements a (CO)-based charge/discharge algorithm scheduling with convex optimization. The algorithm is located in close vicinity with solar PV systems and minimizes the electricity expense of anyone who also owns an ESS. It takes into consideration the usage time volumetric tariff and charge demand tariff for minimizing the electricity expenses. Babacan et al. (2017) mentions that other typical scheduling algorithms do not incorporate the charge demand tariff and volumetric tariff for customers, which have led to development of the algorithm in question. Customers who exceed their load requirements can be provided a supply charge to help in sustaining their energy generation at reasonable cost.

Another system design was implemented within multiple different modes of renewable energy harvesting systems. In managing energy generations from a microgrid comprising PV, wind and biomass harvesters require complex systems especially the energy storage systems. This is due to the irregular nature and power generations of each different type of energy harvesters requiring power backup from non-renewable energy sources such as diesel generators. Singh and Singh (2016) have proposed an algorithm for automation of PV, wind and biomass energy harvesting to store energy within a battery. This algorithm was designed in mind that the energy harvester operates and supply electricity in an off-grid location. From these energy storage systems design mentioned, it is essential for an algorithm for energy storage to take serious accounts of the various parameters in each mode of energy harvesting that is included in a system. When observing these mentioned works, it can be concluded that systems design should be carefully implemented based on what model is used for what configuration of harvester systems. A poor and oversimplified algorithm utilized on a sophisticated renewable energy harvesting system could end up as a liability for consumers demoting the practicality of renewable energy harvesting plants.

\section{Literature review}

The increasing importance of renewable energy deployment, notably solar energy, has urged researchers to examine the economic aspect of solar energy projects. Some of them assessed PV projects economically, but the scale of the projects, the location and the grid connection were different from a study to another. Other studies focused on the cost of electricity from solar power plants, proposing new calculation methods. Furthermore, some researchers examined the financial feasibility of LSS projects, as well as the environmental outcome of such projects.

\section{Economy assessments}

Hussain et al. (2013) carried out the economic assessment for a large-scale solar PV project in UAE. Stochastic analysis with project financial modeling was used for LCOE calculations. Factors that play a crucial role in LCOE are capital expenditure, operation and maintenance cost, system energy production and cost of capital. The available models for project economic evaluation such as NREL CREST solar Model, NREL System Advisor Model and PVSyst are discussed and the underlying drawback of these models is identified as the inability to capture the impact of variability and uncertainty of input parameters on the financial indicators of a project. The study therefore uses an advanced spreadsheet model that is similar to NREL CREST solar model to carry out stochastic analysis. Oracle crystal ball was used to perform the Monte Carlo simulation as it provides the numerous advantages over single-point estimate approach on the 
model. The results were compared with the prevalent tariff for electricity and the LCOE was found to be higher. The study does not take into consideration the subsidies provided for solar PV projects.

Pillai and Naser (2018) carried out the economic assessment of a 1-MW grid-connected PV system optimized for matching the daily peak load by analyzing the LCOE, NPV, PBP and EBPT. PVSyst software was used for design and optimization of the PV system. The annual degradation rate of $0.5 \%$ and lifetime of 30 years was assumed. The results show a positive indication for investment in the project as the LCOE was found to be $43 \%$ less than the present cost of $\mathrm{kWh}$ generation. It was also suggested by the author that with implementation of a cooling system will allow LCOE to experience positive values. However, for the LCOE to become enhanced, the maintenance cost of such system must be equal to per unit of energy generated. This may not be plausible in real situation, since the maintenance cost will always be more due to accounts have to be taken in also cleaning of the solar PV cooling system and their sister components. Solar PV projects can be further supported by favorable policies and subsidies to diversify the generation mix of Bahrain and to be more financially viable at the same time. The study thus provides data on the simulated large-scale solar PV project built in Bahrain to satisfy the growing demand of electricity power in the city. However, some assumptions may need further study in order to fully justify the requirements for constructing large-scale PV stations.

\section{Geographical location and scale}

Zou et al. (2017) carried out the grid parity and technoeconomic analysis for large-scale solar in five different cities in China. A combination of off-grid and on-grid systems was used to analyze the application of residential PV systems. HOMER software was used to carry out the techno-economic analysis. The cost effectiveness of the project is based on the net present cost and the LCOE. The results show that the NPC and LCOE vary for different cities. For cities with low electricity retail costs, LCOE for the said city will be lower. The low retail electricity costs may be due to such location is remote and the residents do not require much electricity in their daily lives. Long distance from the main power grid also contributes to the lower demands of electricity in remote towns and villages. Cities with low solar radiation will have higher LCOE and this contributes to the geographical aspects that affect the LCOE region. The grid parity estimation of PV power generation is based on the learning curve. The LCOE for grid-connected is much lower than for off-grid systems. The study of learning curves shows that the cost trajectories have a similar declining trend in all the cities, but grid parity varies among them. Finally, the sensitivity analysis reveals that regions with high solar radiation are more able to achieve grid parity.

Ramadhan and Naseeb (2011) carried out the cost benefit analysis for a 1-MW PV system in Kuwait. The LCOE with different interest rates and prices were compared with the oil prices to determine the break-even price. This is due to the fact that barrels of oil translate to electrical energy via conventional power plants. Kuwait's energy cost produced via conventional power plants averages around $0.12 \$ / \mathrm{kWh}$ at every $50 \$$ barrel of oil. As such, oil prices can influence the LCOE of the region due to its reliance of the fuel for power generation. The expected benefits Kuwait can gain with implementation of PV system would be reduction of cost in overall energy production of both oil and PV. Greenhouse gas emissions will be lower altogether since less oil will be burn as fuel for electricity generation. The results indicate that as the price of oil increases the LCOE generated by PV system becomes more feasible. Additionally, the economic benefit of PV system and the environmental benefit in terms of reduction of carbon dioxide emissions are also discussed. In terms of socioeconomic, when an area successfully incorporates proper PV harvesting stations, more job opportunities will be available since operations of a PV stations have different skill set requirements compared to a conventional, fuel-driven power plants.

\section{Modeling of PV system and optimization}

Bazilian et al. (2019) discussed in detail the economics of PV power. The study focuses on highlighting the recent reductions in the underlying costs, technological advancements and the market prices for solar PV. The three key parameters discussed are price per watt (capital cost of PV module $\$ / W)$, the LCOE $(\$ / \mathrm{kWh})$ and the concept of grid parity. The availability of various methods to calculate these parameters leads to ambiguity in analysis. The curve for price per watt clearly depicts a dramatic decline in costs in recent years. LCOE results can be misleading and require careful interpretation and calculations. The grid parity for various countries is also discussed. Overall, the study presents the outlook of recent reduction in costs in the PV industry and describes the economic parameters associated with it.

Lai and McCulloch (2019) proposed a new method of levelized cost of delivery (LCOD) to calculate the LCOE for electrical energy storage. The method is developed to overcome the challenges that arise in analyzing the economic projections on complex hybrid systems utilizing PV and EES. A detailed comparison of the levelized cost analysis features for hybrid renewable energy system software such as HOMER Pro, RETScreen Expert and System Advisor Model (SAM) by NREL is carried out. The 
data from Johannesburg and Kenya are used for the case study. The LCOE and LCOD are calculated for two storage technologies namely lithium ion battery and vanadium redox flow battery. The long-term economic impact for storage and PV system is provided and discussed with marginal levelized cost of energy. The results present that with present costs and technical specification, vanadium redox flow battery has a lower LCOD compared to lithium ion at low discount rate for energy storage application in PV systems.

Sabo et al. (2019) proposed a generation demand matching model for evaluating the large-scale implementation of grid-connected PV in power plants in Peninsular Malaysia. The results of the economic analysis present the varying $L C O E$ due to spatial variability in solar radiation in different regions. The calculation for the LCOE of the region for this study considers a variety of data sets. These data sets include digital elevation model raster data from shuttle radar topography mission of DIVAGIS, monthly 24-year average horizontal solar radiation data from NASA and hourly radiation data from Malaysian Agricultural Research and Development Institute (MARDI). The LCOE graphs for different capacity factors and discount rates are included with the LCOE breakeven installed system costs for different states. According to the study, The PV power production in Malaysia experiences $1 \%$ power degradation per year due to the various climates in Malaysia. The cost saving from emission reductions in different states is also included in the study. The spatial data availability is the limiting factor in the application of cost estimations due to the calculation method mentioned by Sabo et al. (2019), relies heavily on the topography, road networks, different forms of electrical demands and demographic data as these data are owned and secured by utility providers and government.

Brankera et al. (2011) reviewed the methodology of correctly calculating the LCOE for solar PV. Within the LCOE calculations, the present LCOE value multiply by the present net costs should be equal to present value of the net costs. The net costs comprise cash outflows (maintenance cost, interests, etc.) and cash inflows (incentives from governments). The major assumptions and misconceptions related to LCOE for PV such as the discount rate, system life, degradation rate, system costs, financing and incentives, grid parity are addressed in the study along with the LCOE methodology. A numerical example for LCOE for Canada is included in the study. It was also stated that the major generation cost for a solar $\mathrm{PV}$ is the start-up cost and upfront costs. The LCOE will be very dependent on the different financing method available in the country. Mohammadi et al. (2018) studied the economic feasibility of a 5-MW grid-connected PV system for 8 different cities in Iran. The LCOE was calculated for 3 different tracking modes namely fixed, 1 -axis tracking and 2-axis tracking. The single axis tracking was the economical option among others. A sensitivity analysis was also carried out to study the impacts of different parameters and identify the most profitable investment. The techno-economic and environmental analysis was carried out using the RETScreen software. The economic analysis included the NPV, PBP, LCOE, IRR and BCR for the eight different cities. The results of the sensitivity analysis show the variation of NPV with varying inflation and discount rates as well as the impact of loan interest rate on PBP and NPV.

Harder and Gibson (2011) examined the potential for a 10-MW PV plant in Abu Dhabi using the RETScreen to predict GHG emissions reduction, energy production and financial feasibility. The RETScreen simulation software is a tool for providing preliminary assessment of renewable energy projects at relatively low cost. This software have deviations of only $0-6 \%$ compared to actual energy productions, therefore it is quite useful tool for simulation of renewable project feasibility and used in conjunction with other simulation tools. The financial analysis includes the net present value, simple payback period and the internal rate of return of the project. The results are that the payback period is 55.4 years while the IRR is $0.5 \%$ and the net present value is negative. The negative net present value projects a poor financial yielding of the project. The paper also highlights the high initial costs and low price of electricity as additional barriers in implementation of the project. El-Shimy (2009) investigated the viability of $10-\mathrm{MW}$ grid-connected PV power plant in Egypt. 29 sites were selected, and the technoeconomic analysis was carried out using RETScreen software. The financial analysis including the NPV, payback period and IRR clearly shows the profitability of the project at the selected sites.

\section{Research gap and contribution}

Many researches have been conducted to determine the economic viability of solar PV projects and to provide new methods to calculate the cost of electricity from energy storage projects. However, no previous study had compared different solar energy systems in different scales, with different energy storage capacities. The current study is a continuation of Laajimi and Go (2019) that focused on the economic effect of increasing or decreasing the installed energy storage capacity in an energy management system, including electricity pricing, grid injection profits, and considering the weather conditions in two locations of a single country. It compares the profitability of energy storage projects to LSS projects, and to energy storage combined with LSS projects. In Laajimi and Go (2019), the work focused on energy storage 
system design with ethical and environmental assessments. In this project, we determine the type of solar energy projects that are most profitable to investors with the current regulations. It also provides an insight of the financial hurdles that energy storage and large-scale solar could be facing in the near future (Table 1).

\section{Methodology}

\section{Power system development and configurations}

In this study, HOMER software has been used to simulate the studied power systems. Homer Pro is a computer modeling software initially developed by the United State (US) National Renewable Energy Laboratory (NREL) and further enhanced by HOMER Energy. It is used to evalu- location. The reference case is simulated for each one of the selected LSS capacities.

" $A$ " is the storage output to the LSS-PV output ratio. This parameter has been varied from 5 to $60 \%$, then the power system components were sized accordingly, and simulated with the different LSS capacities as mentioned in "Power system development and configurations".

For each value of " $A$ ", the needed storage capacity is determined:

$$
\text { Storage capacity }=\frac{\text { LSS }_{\text {Output }} \times A}{365} .
$$

Knowing the energy storage efficiency and the energy storage usable capacity, the number of batteries needed could be determined:

$$
\text { Batteries number }=\frac{\text { Storage capacity }}{\text { Energy storage efficiency } \times \text { storage usable capacity }} \text {. }
$$

ate design options for power systems in different applications, both on-grid and off-grid applications. HOMER, an acronym for "Hybrid Optimization of Energy Resources" simulates power system using three different processes nested together in its core algorithm. It includes power system data input by the user to determine the power systems technical feasibility and life cycle. Multiple power system configurations can be simulated simultaneously and compared to identify the optimal selection based on cost of electricity or net present cost. Lastly, sensitivity analysis can be carried out to perform multiple optimizations based on a wide range of inputs, to determine the uncertainties in the input to the model. The simulated power systems, as shown in Fig. 1, are composed of a conventional generation, the electric load, the LSS installed capacity, an energy storage capacity and a converter. The conventional generation is auto sized by the software according to the electric load. The meteorological data are imported from HOMER including GHI, clearness index, wind velocity and temperature values. In this study, 4 LSS capacities have been considered: 6, 10, 30 and $50 \mathrm{MW}$. These capacities correspond to the maximum of the 4 packages of LSS projects, announced by Energy Commission (2016a,2017a).

\section{Sizing of different power systems}

A primary simulation is necessary to size the power system with its different configurations. As explained in Table 2, the reference case does not include an energy storage capacity. Therefore, only the LSS capacity, the electric load and the converter are introduced to the software. This simulation's aim is to determine the energy output from the LSS installed capacity in the selected
For Scenario 1, the converter is sized according to the energy discharged from the storage in one hour. For Scenario 2, the converter size depends on the LSS output and the storage output. The converter is sized to be able to support the maximum of electricity delivered by each of those components. For each combination of LSS capacity and storage to LSS ratio, Scenario 1 and Scenario 2 have been sized and simulated through HOMER Pro.

\section{PV panel selections}

The generic flat plate PV of HOMER is used in the proposed power system. This model is characterized by a $47^{\circ} \mathrm{C}$ as operating temperature and 25 years as lifetime. Depending on each location, HOMER Pro determines the panel slope automatically. Several characteristics of the PV panel are introduced to run the simulation; a summary is presented in Table 3.

\section{Economic input and calculations}

According to Malaysia Inflation Rate-Forecast (2018), the inflation rate in Malaysia is $3.1 \%$ by 2020 . Since Malaysia is a non-OECD country, the discount rate for renewable energy projects is equal to $10 \%$ (Renewables 2016). These parameters are introduced to HOMER to be considered in the economic analysis. The projects lifetime is set to 21 years, in line with the power purchase agreements in Malaysia (Overview of the FiT System in Malaysia 2018). The economic viability of a particular energy project is evaluated by metrics such as net present worth (NPW), payback period (PB), net present value (NPV) and levelized cost of electricity (LCOE). In the economic analysis, power systems of scenario 1 and scenario 2, as described in Table 2 are 


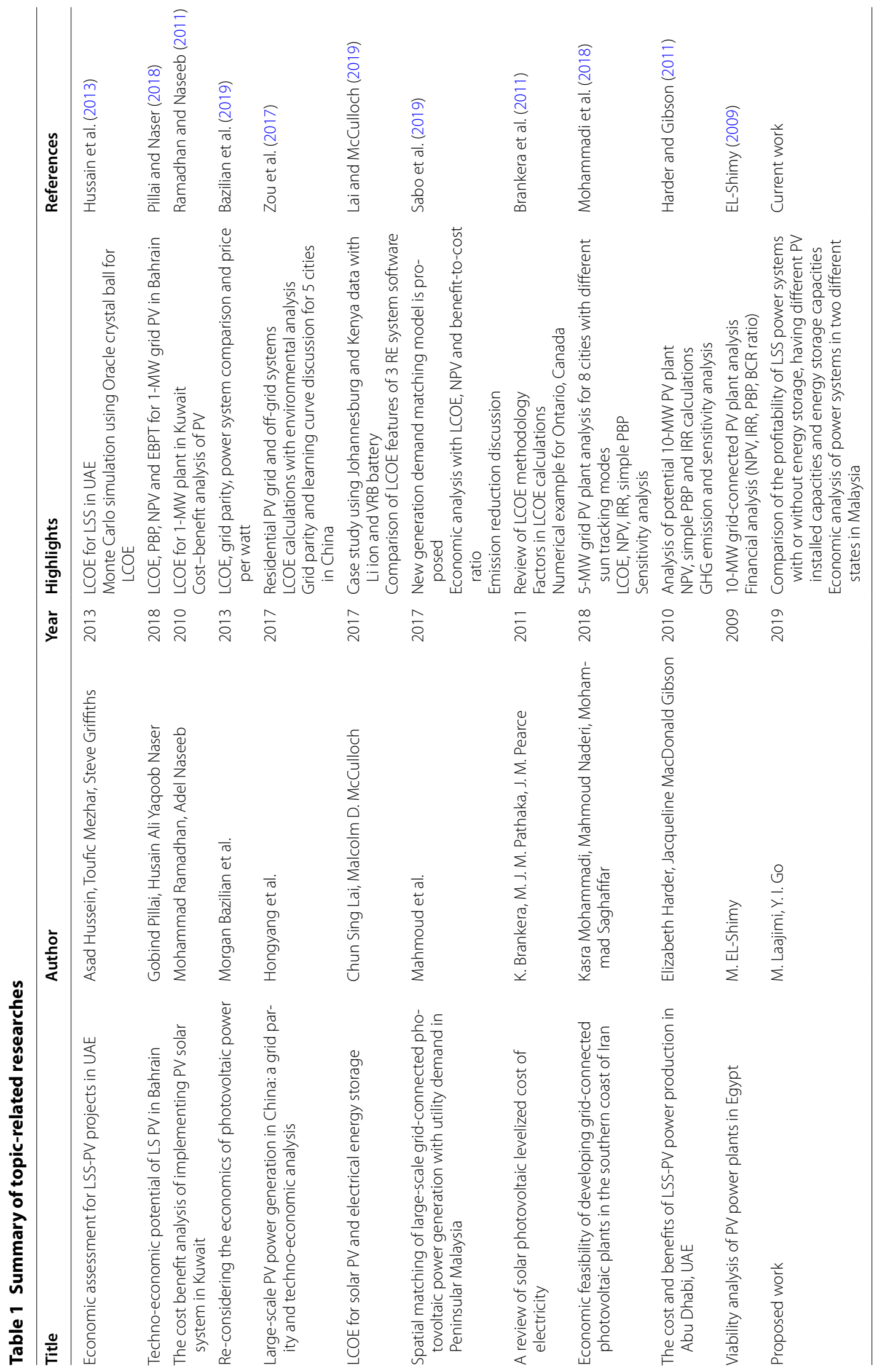




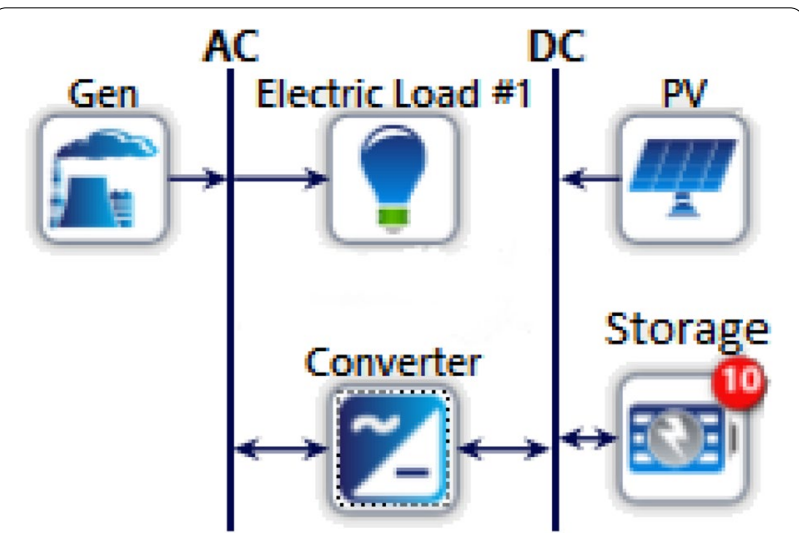

Fig. 1 Simulated power system in HOMER Pro

sized, simulated in HOMER and then analyzed. In all the economic analysis calculations, the capital costs, replacement costs, O\&M costs and salvage values (Salvage Value 2018) of the components of the power system, except the conventional power generation, are retrieved from HOMER Pro simulations results. These values, combined with the energy generated, and the energy output from the storage, are used to calculate the levelized cost of electricity, the net present worth, the net present cost and the payback period. The economic analysis has been carried out in two states to compare the economic outcomes with different average values of solar irradiation. The energy storage technology used in the simulated power systems is the 1-MWh

\section{Net present worth}

It is an economic tool used to analyze the profitability of the project. Present value is defined as the current equivalent value of a set of future cash flows considering the time value of money. It is the value of all future cash flows (positive and negative) over the entire life of an investment discounted to the present. A positive value indicates that the project is economically feasible while a negative value shows that it is not (Net Present Value (NPV) 2019). The general equation of a given project is defined as follows:

$$
\mathrm{NPW}=\sum_{t=1}^{T} \frac{C_{t}}{(1+r)^{t}}-C_{0} .
$$

With:

- $C_{t}$ : net cash flow during the project lifetime,

- $C_{0}$ : total initial investment,

- $r$ : real discount rate,

- $t$ : project lifetime, equal to 21 years (Che Mud 2019).

\section{LSS with storage projects}

For the case of LSS with storage projects, a part of the financial incomes is ensured by the injection of the electricity generated by LSS to the grid during the daytime, while the other part is ensured by discharging the stored energy at the night peak time. $C_{t}$ is then calculated by the following equation:

$$
C_{t}=(1-A) \times \mathrm{LSS}_{\text {Output }} \times \mathrm{PPA}_{\text {Price }}+\text { storage }_{\text {Output }} \times \text { storage income per } \mathrm{kWh} \text {. }
$$

zinc bromide battery. It is a $600-\mathrm{V}$ zinc bromide flow battery with $3000 \mathrm{~kW}$ as maximum discharge power. The cost of energy storage is RM 400/kWh (USD 97/ kWh) (XE: Convert MYR 2019). This choice is based on the great rated capacity of the battery. Furthermore, the high efficiency, the full depth of discharge, the fast charging and the excellent value for money insured by this technology at this scale make it very competitive in the future energy storage projects worldwide (Poullikkas 2013; International Renewable Energy Agency 2017).

\begin{tabular}{|c|c|c|c|}
\hline Parameter & Value & Unit & References \\
\hline Operating temperature & 47 & ${ }^{\circ} \mathrm{C}$ & HOMER Pro \\
\hline Efficiency & 19 & $\%$ & $\begin{array}{l}\text { Solar panel efficiency | } \\
\text { Solar System Malaysia } \\
\text { (2012) }\end{array}$ \\
\hline Derating factor & 80 & $\%$ & PV Derating Factor (2018 \\
\hline Lifetime & 25 & Years & HOMER Pro \\
\hline Energy cost & 727 & USD/kWh & SEDA (2016) \\
\hline Performance degradation & 1 & $\%$ & Ye et al. (2014) \\
\hline
\end{tabular}

Table 3 Characteristics of the PV panel

\begin{tabular}{|c|c|c|c|}
\hline a & Scenario 1 & Storage only & This investment type includes only the energy storage and the proper converter \\
\hline $\mathrm{b}$ & Scenario 2 & LSS with storage & $\begin{array}{l}\text { This investment includes LSS, energy storage and the converter. The energy } \\
\text { generated by the LSS will be partially injected to the grid, and partially charg- } \\
\text { ing the storage }\end{array}$ \\
\hline C & Reference case & LSS Only & This is the reference case, including only the LSS capacity planned by 2020 \\
\hline
\end{tabular}

Table 2 Description of the different investment types to be compared in the economic analysis 
The electricity injected to the grid is sold at the power purchase agreement price for the whole period of the project. Since the agreement price is not announced for the shortlisted projects, it is assumed to be the average of the prices proposed by the investors for projects with the same LSS capacity (Commission 2016b,2017b). Consequently, the $\mathrm{PPA}_{\text {price }}$ in Pahang is equal to RM $0.4354 / \mathrm{kWh}$ (USD $0.1055 / \mathrm{kWh}$ ) for $50-\mathrm{MW}$ projects, RM 0.4194/kWh (USD 0.1096/kWh) for 30-MW projects, RM 0.4222/kWh (USD 0.1023/kWh) for 10-MW projects and RM $0.4609 / \mathrm{kWh}$ (USD $0.1117 / \mathrm{kWh}$ ) for $6-\mathrm{MW}$ projects. The financial income from storing a kWh of solar-generated electricity and then discharging it, is the difference between the price of the kWh discharged from the storage and sold at the peak time, and the LCOE of the storage. The electricity discharged from the storage at the peak time, is assumed to be sold at the TNB peak price (Azmana et al. 2017), that is equal to RM $0.584 / \mathrm{kWh}$ (USD $0.1415 / \mathrm{kWh}$ ). Since the investment includes LSS-PV and storage, the cost of electricity charged to the storage is equal to the LCOE from LSS-PV, without any additional margin. The initial costs include the cost of LSS, storage and converter. The values are retrieved from HOMER simulation results.

\section{Storage projects}

For the case of storage projects, the equation of NPW remains the same, but $C_{t}$ is calculated according to the following equation:

$$
C_{t}=\text { storage }{ }_{\text {Output }} \times \text { storage income per } \mathrm{kWh} \text {. }
$$

Financial income from storing and then discharging a $\mathrm{kWh}$ is calculated by the same way used for the LSS with storage case, with the only difference that the cost of charging the storage is equal to the price of buying electricity from the grid. It is assumed in the current research that the energy storage solution is supposed to solve the issue of generating electricity at the day off-peak time from solar irradiation, by storing it and delivering it at the night peak demand time. Then, even the electricity is purchased from the grid, the storage is assumed to be charged during daytime when solar energy is available. The cost of buying electricity is equal to the mid-peak $\mathrm{kWh}$ price of TNB (TNB ENHANCED TIME OF USE (ETOU) 2018), that is equal to RM $0.357 / \mathrm{kWh}$ (USD $0.0865 /$ $\mathrm{kWh}$ ). The price of buying electricity is used for all the days of the week. The electricity time zones are shown in Fig. 2.

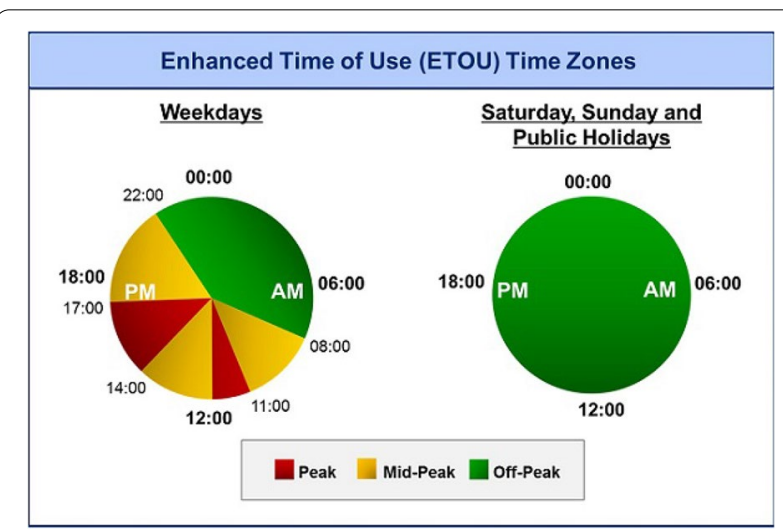

Fig. 2 Tenaga National Berhad enhanced time of use of electricity (TNB ENHANCED TIME OF USE (ETOU) 2018)

The initial costs depend on every single case simulated. Varying the value of A implies different storage capacities, different batteries quantities and different converter sizes. For storage projects, the initial cost is calculated without LSS costs, including only the batteries costs and the converter costs. The storage initial cost can be different from the storage costs of LSS with storage projects, because of the converter size that can be bigger or smaller than the one used for LSS with storage project.

\section{LSS projects (reference case)}

The LSS projects, under HOMER simulation, include only the PV and the converter. These projects are serving as a reference cases to compare with the storage projects and LSS with storage projects. The cash flow of such projects is ensured by selling the electricity generated by LSS to the grid, at the PPA price. The cash flow equation is as follows:

$$
C_{t}=\text { LSS Output } \times \text { PPA Price. }
$$

The initial costs include the cost of PV array and the appropriate converter.

\section{Net present cost}

For each power system, the different costs of each component are calculated for the whole project lifetime. Net present cost also defined as life-cycle cost of a component. It is the present value including the costs of installation and operation of the component throughout a project lifetime which minuses the present value of all revenues. The model calculates the net present cost of each component in the system. The initial costs, the replacement costs and the O\&M costs are calculated by HOMER as follows: 


$$
\mathrm{NPC}_{\text {Component }}=\sum_{t=1}^{21} \frac{\text { Costs }}{(1+r)^{t}} .
$$

With:

- $t$ : project lifetime in years,

- $r$ : real discount rate.

The real discount rate is given by the following formula:

$$
r=\frac{r^{\prime}-f}{1+f}
$$

With on investment for the producer (Return on Investment (ROI) 2019).

\section{For LSS projects (reference case)}

The LCOE of a project is the sum of its lifetime costs, divided by the sum of the generated energy by this project. The LCOE of large-scale solar PV is equal to:

$$
\mathrm{LCOE}(\mathrm{PV})=\frac{\sum_{1}^{21} \text { LSS costs }}{\sum_{1}^{21} \text { LSS output }}
$$

\section{For storage projects}

According to Pawel (2014), LCOE of a storage system is calculated as follows:

$$
\mathrm{LCOE}(\mathrm{ST})=\frac{\sum_{1}^{21} \text { Storage costs }}{\sum_{1}^{21} \text { Storage output }}+K_{t} \times \frac{\text { Initial electricity price }}{\text { Storage efficiency }}
$$

- $r^{\prime}$ : discount rate,

- $f$ : inflation rate.

The salvage value calculated by HOMER is the remaining value of a component at the end of the project lifetime (Malaysia Inflation Rate-Forecast 2018). It is included in the calculation of the NPC of a power system. The NPC of the entire system is calculated by HOMER as follows:

$$
\mathrm{NPC}_{\text {System }}=\sum_{t=1}^{21}\left(\mathrm{NPC}_{\text {Components }}-\mathrm{CSV}\right) \text {. }
$$

With CSV: sum of the components salvage value.

\section{Levelized cost of electricity}

LCOE is a measurement tool that is used to compare different power generation projects and is measured in cost
With:

- $K_{t}:$ the increase of electricity price over the project period,

- Initial electricity price: the cost of $1 \mathrm{kWh}$ at the beginning of the project.

According to the Energy Commission (Electricity Statistics-Electricity Average Selling Price 2019), the electricity average selling price for industrial usage, increased from 2010 to 2014 with an annual average of $4.7 \%$. This annual average has been used to calculate the LCOE of storage projects.

\section{LSS with storage projects}

According to Azmana et al. (2017), the LCOE of LSS with storage is as follows:

$$
\mathrm{LCOE}(\mathrm{LSS}+\mathrm{ST})=\frac{\mathrm{LCOE}(\mathrm{PV})}{1-A(1-\text { Storage efficiency })}+\frac{A \times \text { Storage efficiency } \times \operatorname{LCOE}(\mathrm{St})}{1-A(1-\text { Storage efficiency })} .
$$

per kilowatt hour (kWh). It covers all investment and operational costs over the system lifetime, including the replacement of equipment. LCOE can be considered as a benchmarking tool used to assess the cost effectiveness of different energy generation technologies by removing biases between the technologies. LCOE is also used to determine the feed-in-tariff (FiT) and negotiate power purchase agreements (PPA), which cover the potential risk to the investors in adopting new and relatively expensive technologies, by assuring a reasonable return
In the case of LSS with storage projects, the LCOE(St) is calculated with an initial electricity cost equal to the LCOE from LSS.

\section{Payback period}

Payback period is used to determine the expected time required for the project to recover its initial cost. A shorter PBP time will be better, because the project recovers the initial cost in a short timeframe. PBP is equal 
to the time that is required to make NPV equal to zero. To calculate PP, it has to verify whether the total NPV of the project over its lifetime is a negative value. If it is, that means the project is not feasible (Investopedia 2019).

The PP in this project is calculated according to the following equation:

$$
\text { Payback period }=\frac{C_{0}}{C_{1}} .
$$

With:

- $C_{0}$ : initial costs of a given project,

- $C_{1}$ : the cash flow of the first year.

\section{Results and discussion}

Pahang economic analysis results

Net present worth

For each LSS capacity, the value of " $A$ " has been varied from 5 to $60 \%$. For each case, the storage and the converter are sized, and the project is simulated by HOMER. The results such as the costs, the storage output and the LSS output are retrieved from HOMER simulation results. Those results are used to calculate the NPW of each project for the three types of investment. The NPW of the different investment cases is presented in Figs. 3 and 4. Figure 3 shows the comparison of NPW between different LSS capacities with different values of " $A$ ", for each type of

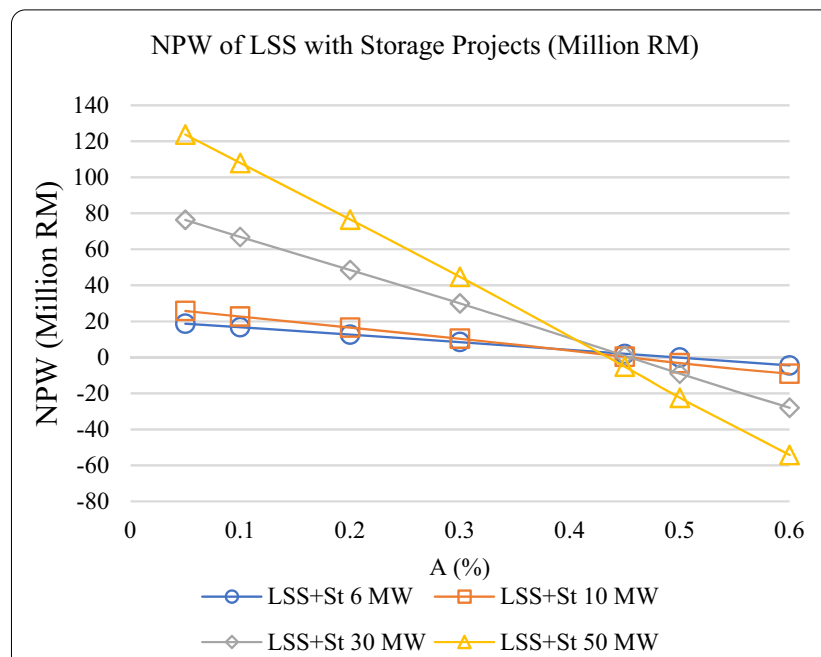

a

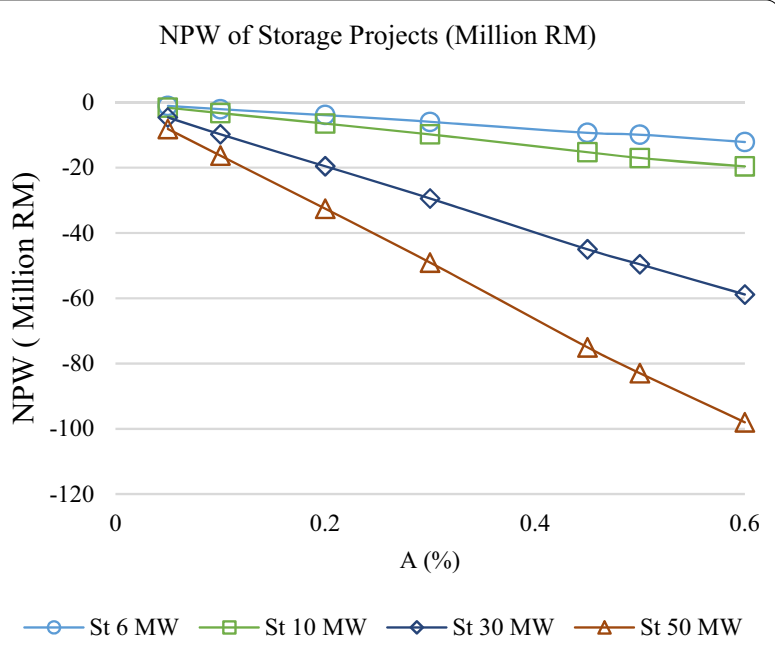

b

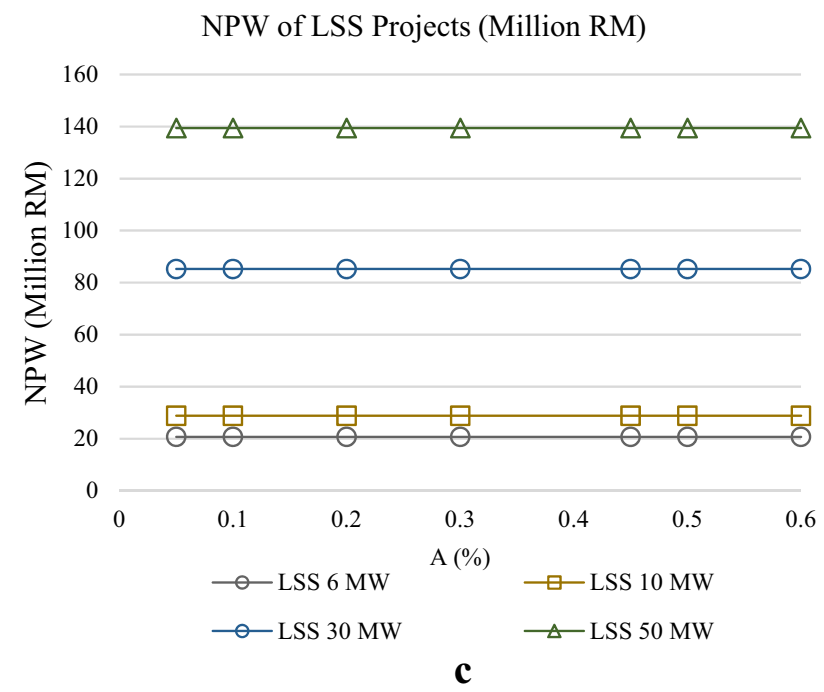

Fig. 3 Net present worth of different LSS capacities with variation of "A" in Pahang. a LSS with storage projects, b storage projects, $\mathbf{c}$ LSS projects 


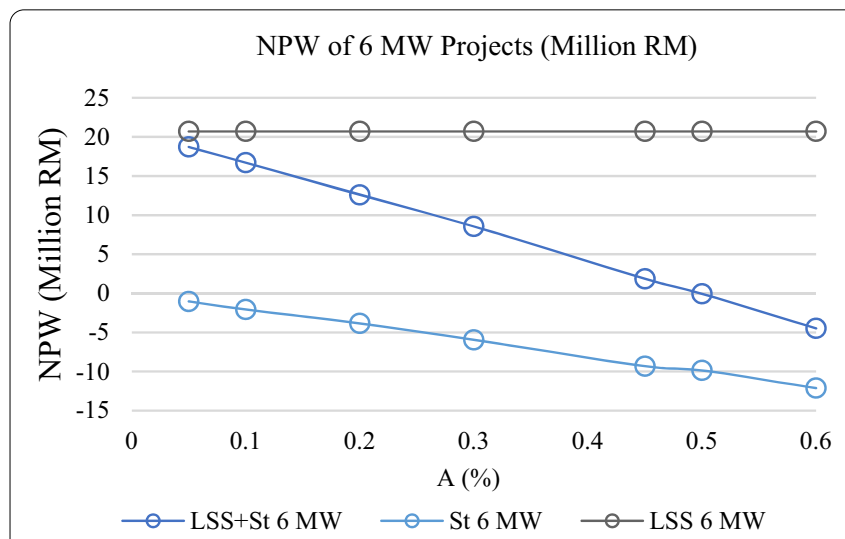

a

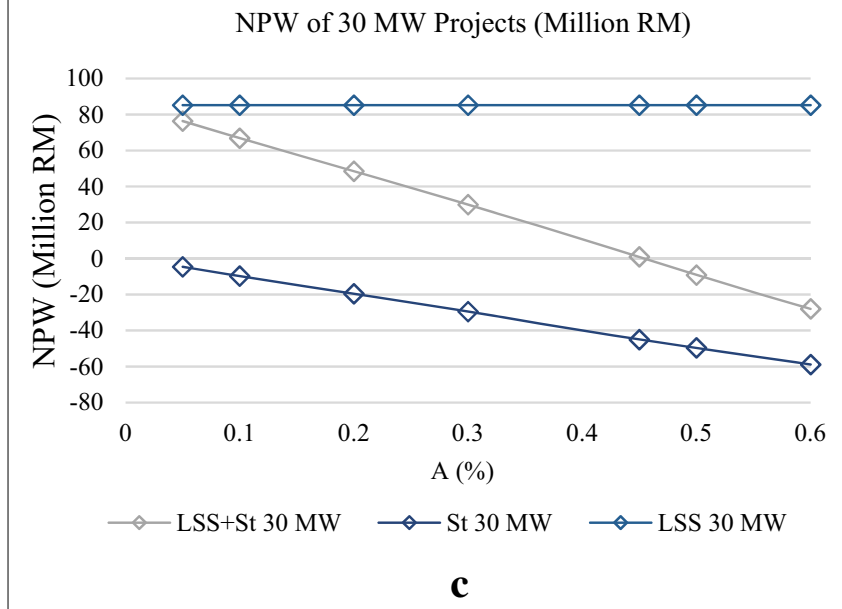

Fig. 4 Net present worth of the different investment types for each LSS capacity in Pahang. a 6-MW projects, b 10-MW projects, c 30-MW projects, d 50-MW projects

investment. For LSS + St projects, and for " $A$ " lower than $43 \%$, the NPW of $50-\mathrm{MW}$ projects are higher than those of $30-\mathrm{MW}$ projects, $10-\mathrm{MW}$ projects and $6-\mathrm{MW}$ projects, respectively. The NPW of LSS + St projects are at maximum rates with low values of " $A$ ". Starting from $A=43 \%$, the NPW of all the projects becomes negative, with the lowest value for $50-\mathrm{MW}$ projects, followed by $30-\mathrm{MW}$ projects, $10-\mathrm{MW}$ projects and finally $6-\mathrm{MW}$ projects. For storage projects, Fig. 3b shows that the NPW is negative for all the cases. The lowest NPW is for 50-MW projects, while the highest NPW is for 6-MW projects. For all the LSS capacities, the higher the value of " $A$ ", the lower the NPW of storage projects. For LSS projects, Fig. 3c shows that NPW is higher with greater LSS capacities.

Figure 4 shows the comparison between LSS with storage projects, storage projects and LSS projects, with different values of " $A$ " for each LSS capacity. For all the LSS capacities; 6, 10, 30 and $50 \mathrm{MW}$, LSS projects have the higher NPW, followed by LSS + St projects and then storage projects. This is due to the cost of electricity for LSS projects and the efficiency losses of the storage. With low values of " $A$ ", the NPW of $\mathrm{LSS}+\mathrm{St}$ are closer to the NPW of LSS projects. With higher values of " $A$ ", the NPW of LSS + St projects is closer to the NPW of storage projects. The LSS + St $6 \mathrm{MW}$ is the less profitable project, and the LSS $50 \mathrm{MW}$ is the most profitable. For all the LSS capacities, the storage only projects are not profitable. This is due to the electricity cost as well. It is assumed to be equal to the price of electricity of the mid-peak time (Che Mud 2019), $0.357 \mathrm{RM} / \mathrm{kWh}$ (USD $0.0865 / \mathrm{kWh}$ ). In order for such project to be profitable, the electricity cost must be very low compared to the current electricity prices in Malaysia. 


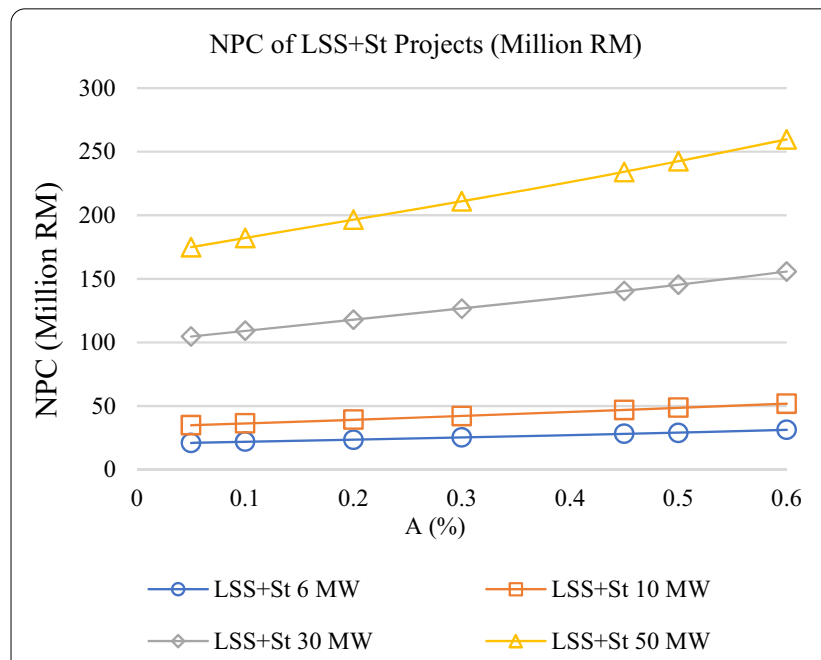

a

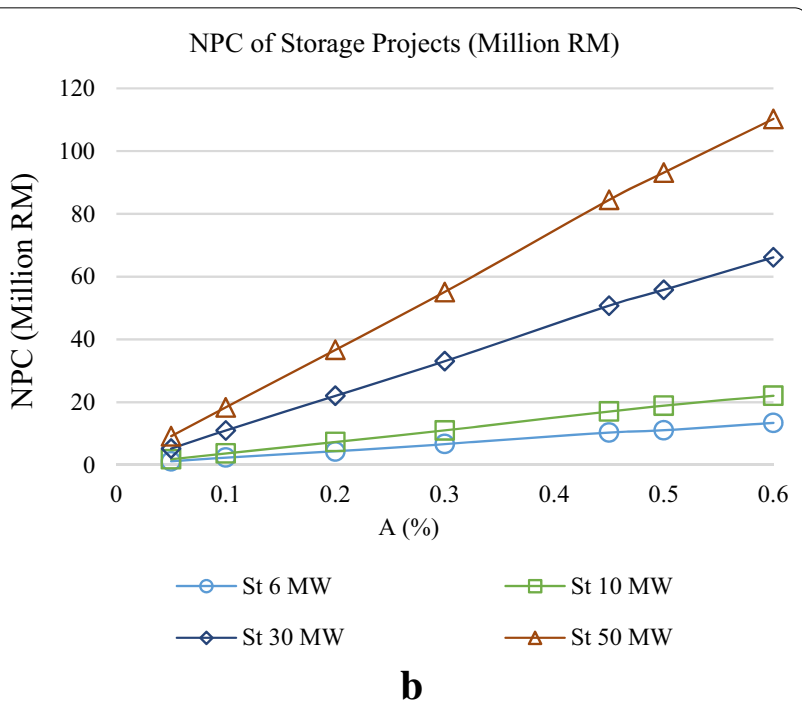

NPC of LSS Projects (Million RM)

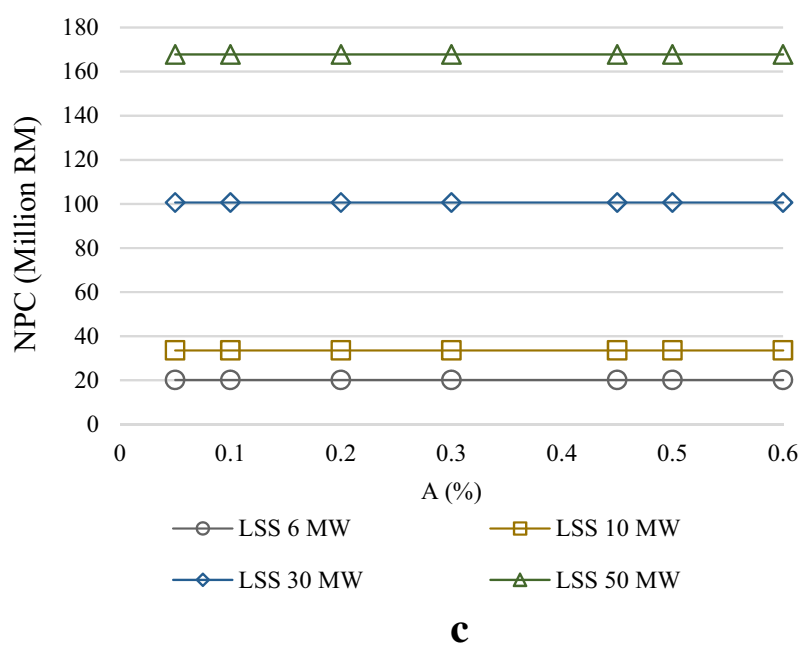

Fig. 5 Net present cost of different LSS capacities with variation of A. a LSS with storage projects, $\mathbf{b}$ storage projects, $\mathbf{c}$ LSS projects

\section{Net present cost}

The NPC of the investment cases in Pahang is presented in Figs. 5 and 6.

Figure 5 shows the comparison of NPC between different LSS capacities with different values of " $A$ ", for each type of investment. For LSS + St projects, shown in Fig. 5a, the NPC of 50-MW projects starts from RM 175 Million (USD 42.4 Million) for $A=5 \%$, to RM 260 Million (USD 63 Million) for $A=60 \%$. For $6-\mathrm{MW}$ projects, the NPC ranges from RM 21 Million (USD 5.09 Million) to RM 31 Million (USD 7.51 Million) for the same values of " $A$ ". For storage projects, shown in Fig. $5 \mathrm{~b}$, the $50-\mathrm{MW}$ projects have the highest cost, ranging from RM 9.2 Million (USD 2.23
Million) for $A=5 \%$ to RM 110 Million (USD 26.66 Million) for $A=60 \%$. The lowest costs are for 6-MW projects, ranging from RM 1.2 Million (USD 291000 ) for $A=5 \%$ to RM 13.4 Million (USD 3.25 Million) for $A=60 \%$. For LSS projects, shown in Fig. 5c, $50 \mathrm{MW}$ projects have an NPC equal to RM 168 Million (USD 40.72 Million), followed by 30-MW projects with an NPC equal to RM 101 Million (USD 24.5 Million), then 10-MW projects with an NPC equal to RM 34 Million (USD 8.24 Million), and finally $6-\mathrm{MW}$ projects that have the lowest net present cost, equal to RM 20 million (USD 4.85 Million).

Figure 6 shows the comparison of NPC between the three types of investment for each LSS capacity. It can be 


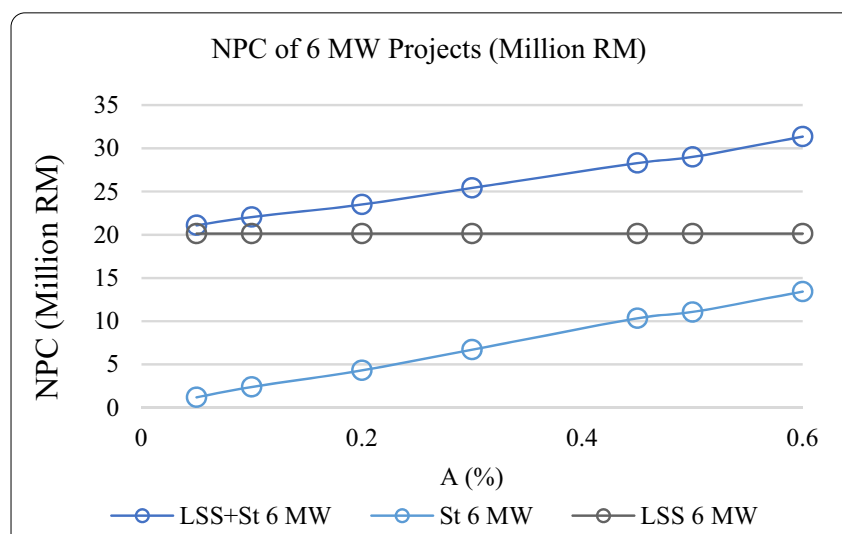

$\mathbf{a}$

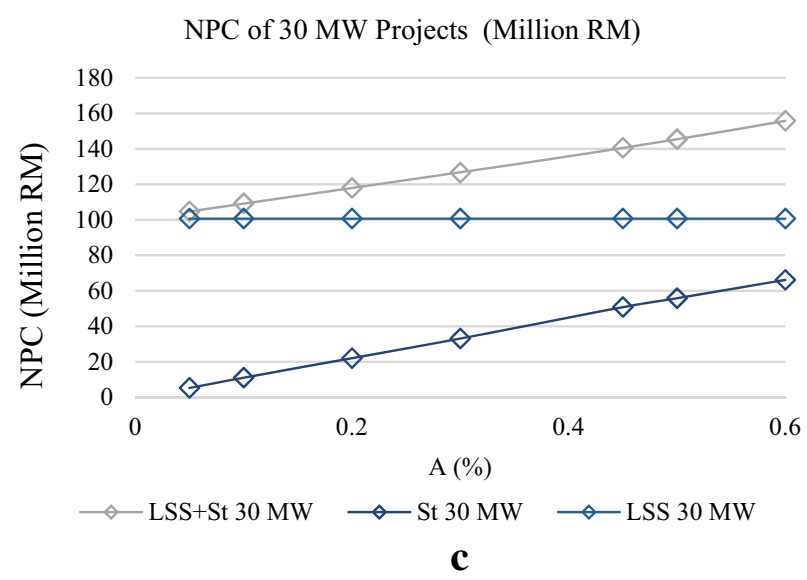

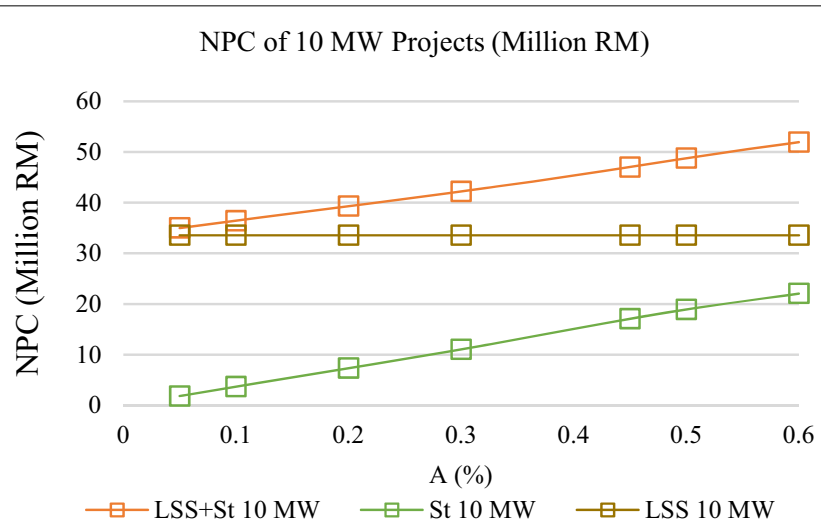

b

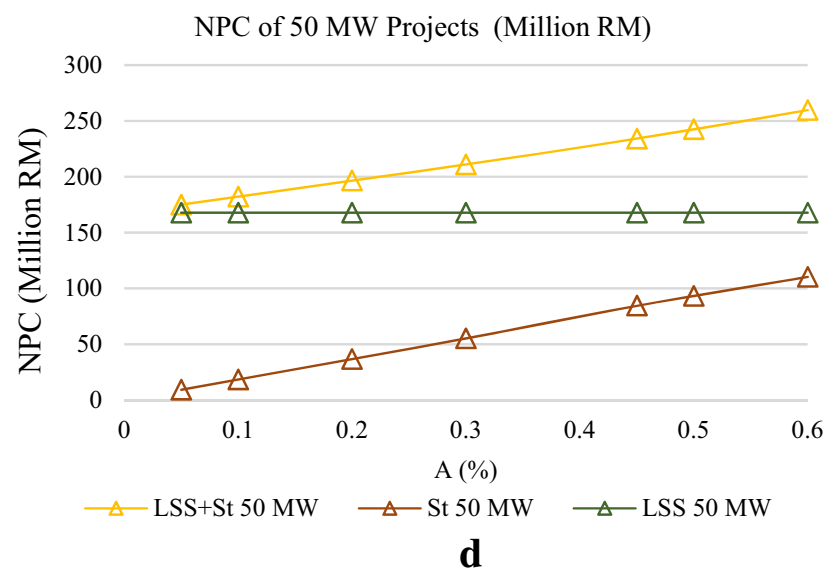

Fig. 6 Net present cost of the different investment types for each LSS capacity. a 6-MW projects, b 10-MW projects, c 30-MW projects, d 50-MW projects

seen from the graph that for each LSS capacity, LSS + St projects have higher NPC value than LSS projects, which are higher than storage projects as well. With low values of " $A$ ", the NPC of LSS + St projects and LSS projects is close to each other. With greater values of " $A$ ", the NPC of LSS projects are closer to the NPC of storage projects. For each LSS capacity, the NPC of LSS + St projects and storage projects increases with high values of " $A$ ". LSS projects are not concerned since the project does not include energy storage, and " $A$ " as explained previously is the ratio of storage output to the electricity generated by PV.

\section{Levelized cost of electricity}

The levelized cost of electricity of the different projects is presented in Figs. 7 and 8. Figure 7 shows the comparison of the levelized cost of electricity for different
LSS capacities with different values of " $A$ ", for each type of investment. For LSS + St projects shown in Fig. $7 \mathrm{a}$, the lowest values of LCOE are guaranteed with $A=5 \%$, for all the LSS capacities. With $A=5 \%, 30-\mathrm{MW}$ projects have the cheapest electricity, equal to RM $0.2484 / \mathrm{kWh}$ (USD 0.0602/kWh); followed by 6-MW projects with an LCOE equal to RM $0.2488 / \mathrm{kWh}$ (USD $0.0603 / \mathrm{kWh}$ ), 10-MW projects with an LCOE equal to RM $0.2489 / \mathrm{kWh}$ (USD $0.0603 / \mathrm{kWh}$ ), and finally $50-\mathrm{MW}$ projects with LCOE equal to RM $0.2602 / \mathrm{kWh}$ (USD $0.0630 / \mathrm{kWh}$ ). Increasing the storage to LSS ratio results in the increase of LCOE, exceeding RM $0.47 / \mathrm{kWh}$ (USD $0.1139 / \mathrm{kWh}$ ) for $A=60 \%$. For storage projects, the variation of " $A$ " for $10-\mathrm{MW}$ LSS capacity does not have a considerable impact to the LCOE. All the values are around RM $0.85 / \mathrm{kWh}$ (USD 0.2060/kWh). For LSS projects, shown in Fig. 7c, 50 MW projects have an LCOE equal to RM $0.24 / \mathrm{kWh}$ (USD 


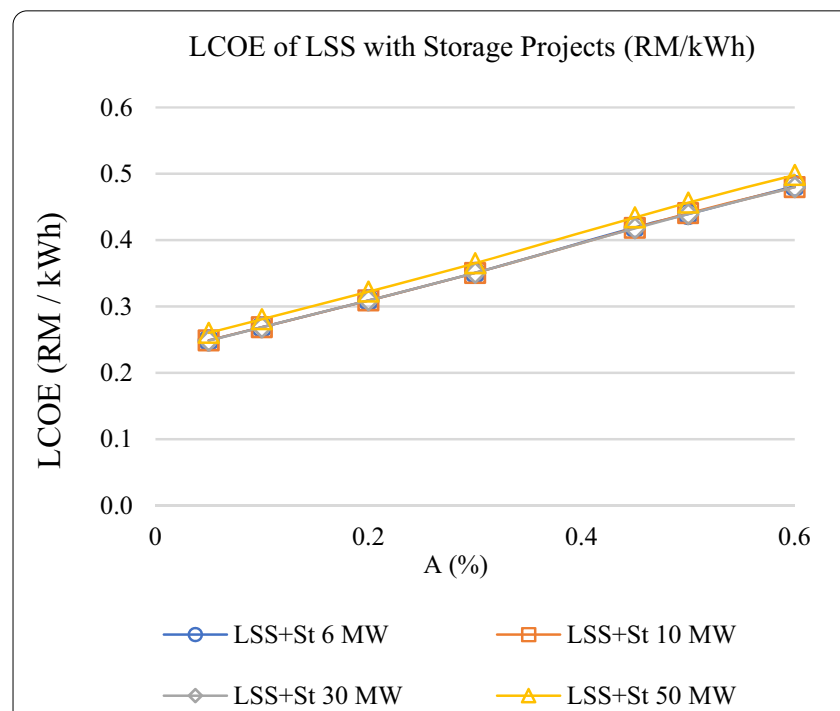

a

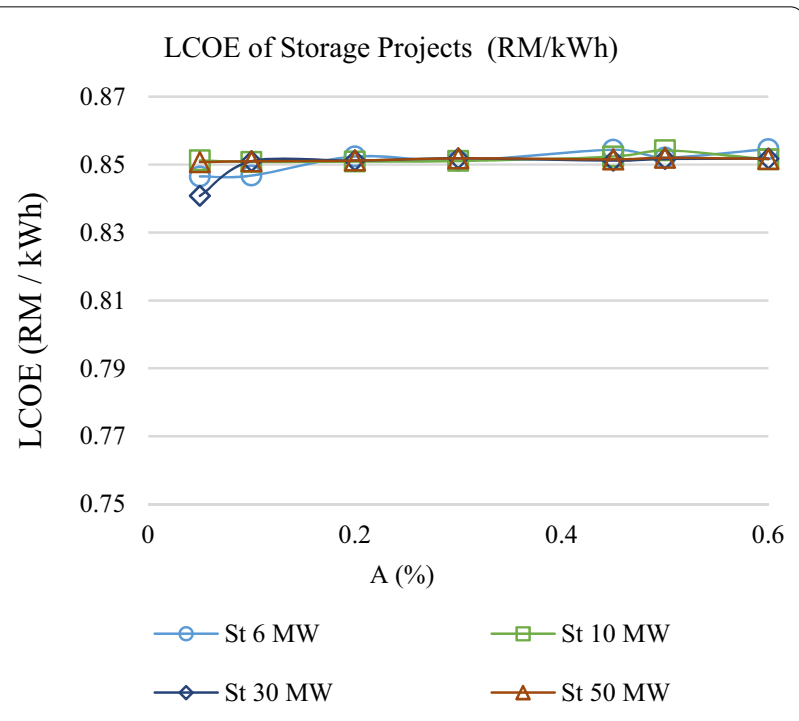

b

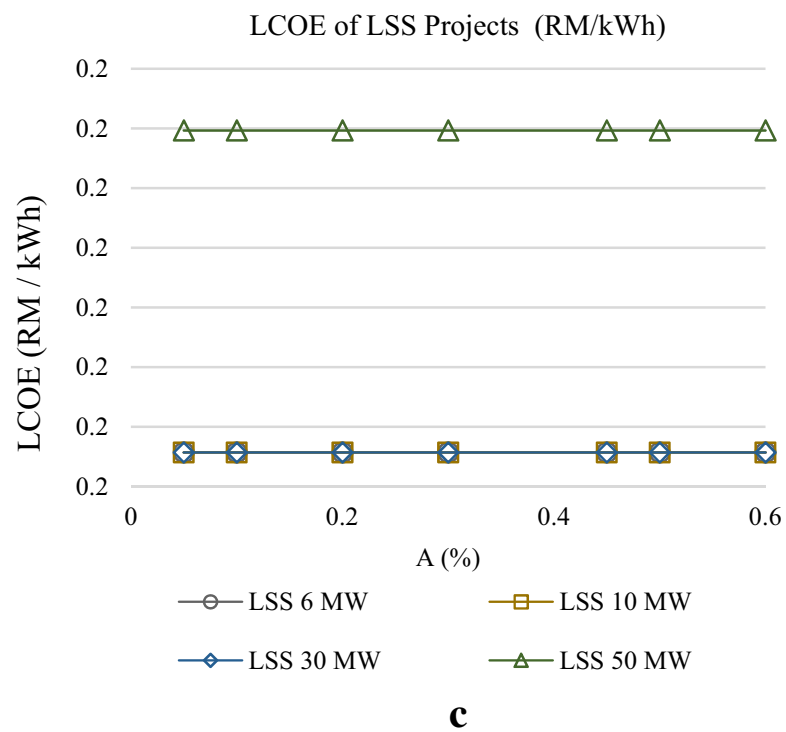

Fig. 7 Levelized cost of electricity of different LSS capacities with variation of "A". a LSS with storage projects, $\mathbf{b}$ storage projects, $\mathbf{c} L S S$ projects

0.0582/kWh), while 30, 10 and $6 \mathrm{MW}$ have an LCOE equal to RM $0.23 / \mathrm{kWh}$ (USD $0.0557 / \mathrm{kWh}$ ).

Figure 8 is a comparison of NPC between the three types of investment for each LSS capacity. The LCOE of LSS projects is relatively low compared to LCOE of LSS + St projects and LCOE of storage projects. It is around RM $0.23 / \mathrm{kWh}$ (USD $0.0557 / \mathrm{kWh}$ ) for most of the investment cases. The LCOE of storage projects is the highest for all the investment cases. The LCOE of LSS + St projects is close to LCOE of LSS projects with lower values of " $A$ ". The difference is RM $0.02 / \mathrm{kWh}$ (USD $0.0048 / \mathrm{kWh}$ ) for $A=5 \%$, while it is equal to RM 0.288 / kWh (USD $0.0698 / \mathrm{kWh}$ ) for $A=60 \%$.

\section{Payback period}

The PP of the different investment cases is shown in Figs. 9 and 10.

Figure 9 shows the comparison of the payback period for different LSS capacities with different values of " $A$ ", for each LSS + St and LSS investment. It is less than 6 years for $A=5 \%$ for all the cases. For $A=60 \%, 50,30$ and 10-MW LSS + St projects have a payback period of more than 13 years, while 6-MW LSS + St projects PP is 12 years and 6 months. LSS projects have shorter payback period, equal to 5 years 5 months.

The gap between the PP of storage projects and PP of $\mathrm{LSS}+\mathrm{St}$ projects is significantly reduced with low " $A$ " 


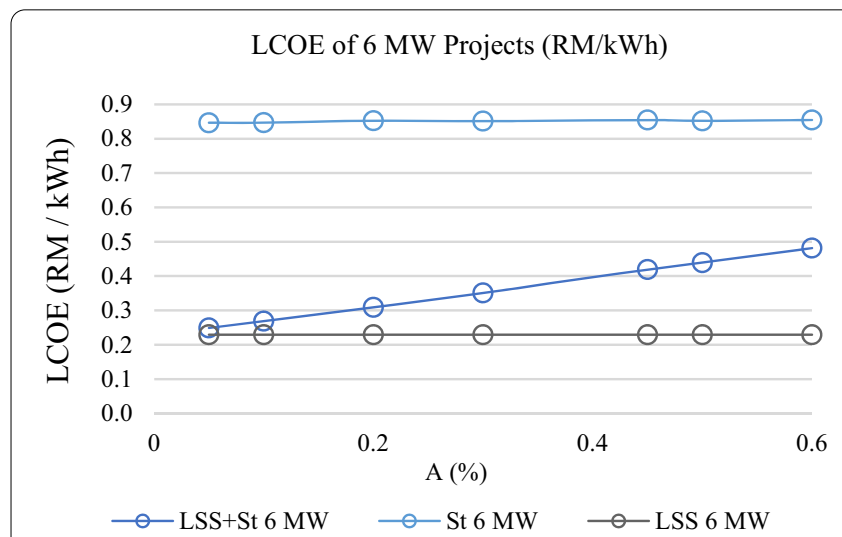

$\mathbf{a}$

LCOE of $30 \mathrm{MW}$ Projects $(\mathrm{RM} / \mathrm{kWh})$

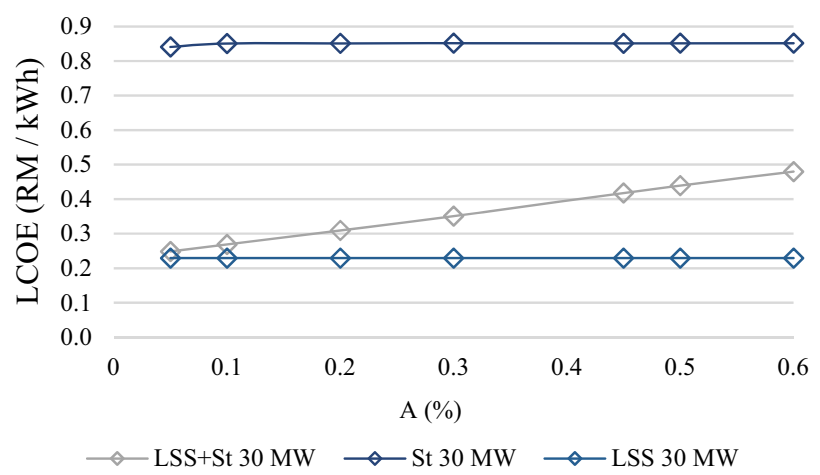

c

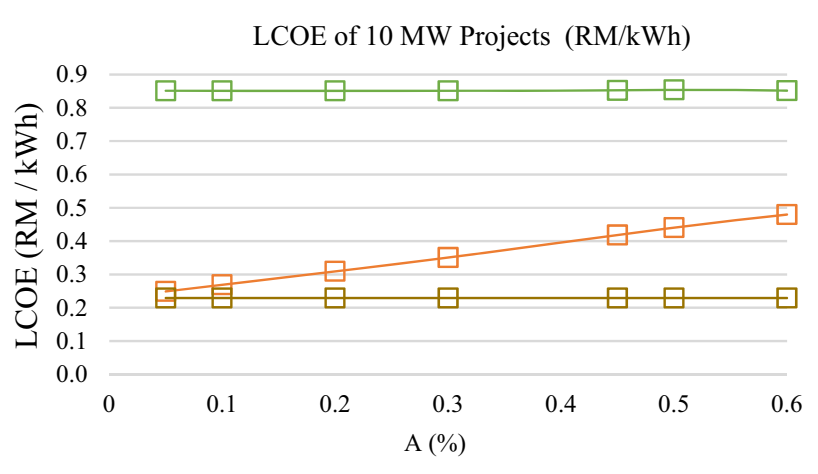

$\because$ LSS+St $10 \mathrm{MW} \longrightarrow$ - St $10 \mathrm{MW} \longrightarrow$ - LSS $10 \mathrm{MW}$

b

LCOE of $50 \mathrm{MW}$ Projects $(\mathrm{RM} / \mathrm{kWh})$

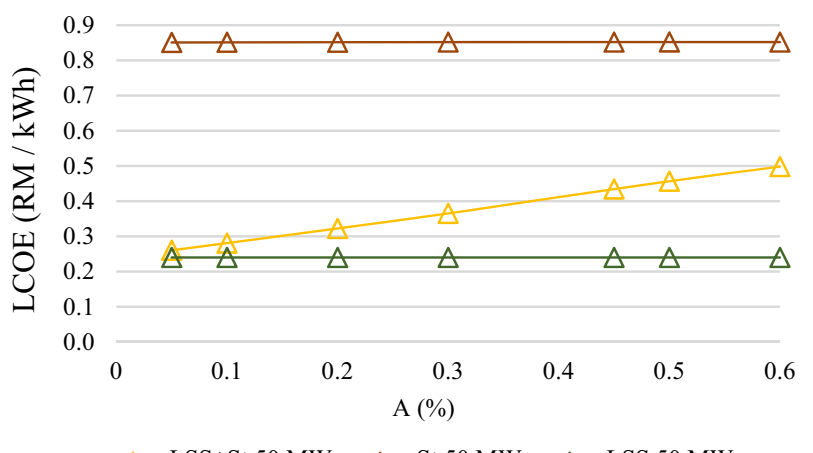

$\triangle$ LSS+St $50 \mathrm{MW} \triangle$ St $50 \mathrm{MW} \triangle$ LSS $50 \mathrm{MW}$

\section{d}

Fig. 8 Levelized cost of electricity of the different investment types for each LSS capacity. a 6-MW projects, b 10-MW projects, c 30-MW projects, d 50-MW projects

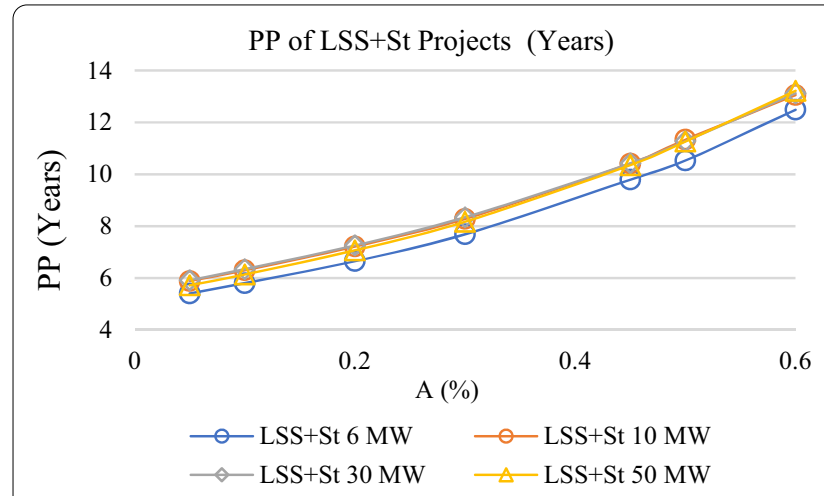

a

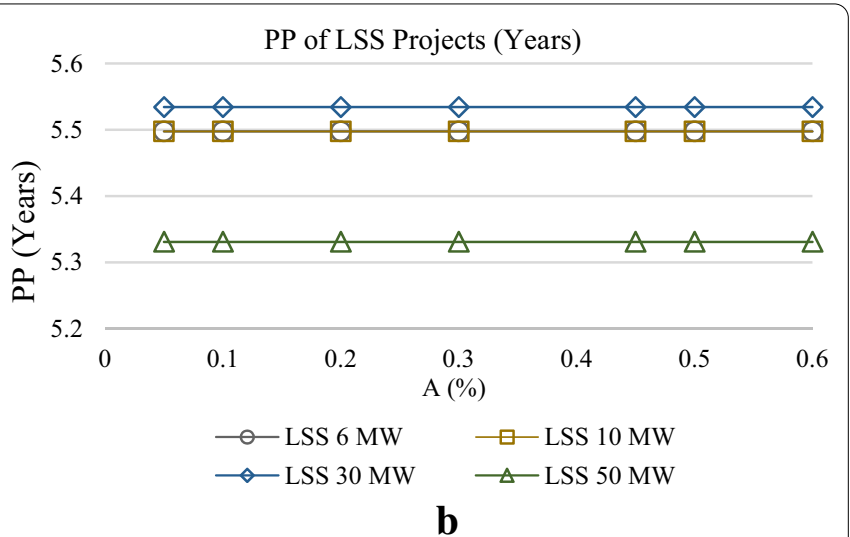

b

Fig. 9 Payback period of different LSS capacities with variation of "A". a LSS with storage projects, $\mathbf{b} L S S$ projects

values. For $A=5 \%, 50,30$ and 10-MW LSS projects and LSS + St projects PP have a difference of around 5 months. For 6-MW capacity, LSS and LSS +St projects PP have a difference of 1 month. The higher the value of " $A$ ", the longer the payback period of LSS +St compared to LSS projects. For $\mathrm{A}=60 \%$, the payback period of $\mathrm{LSS}+\mathrm{St}$ is around three 


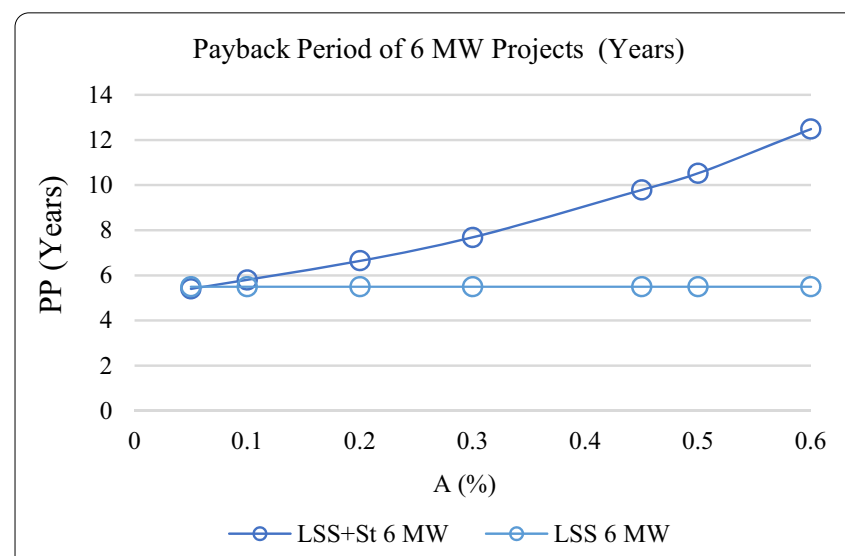

a

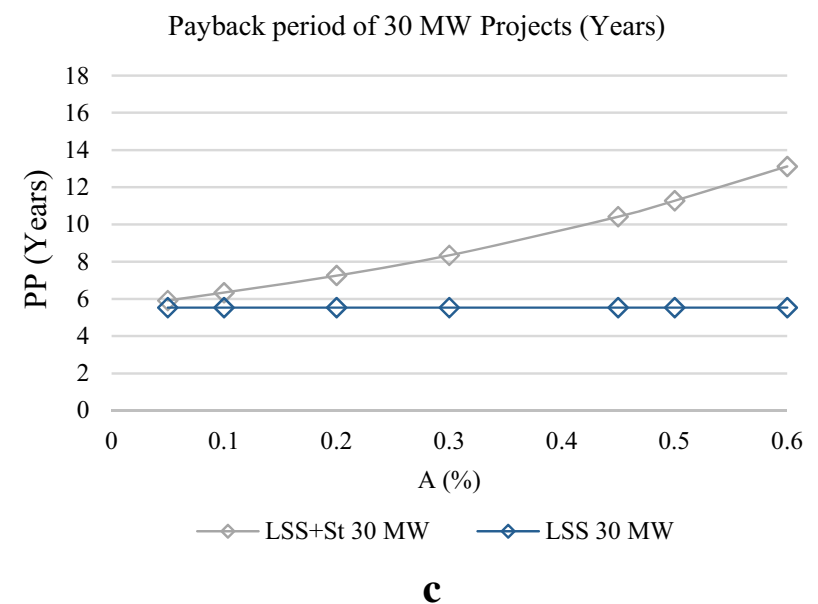

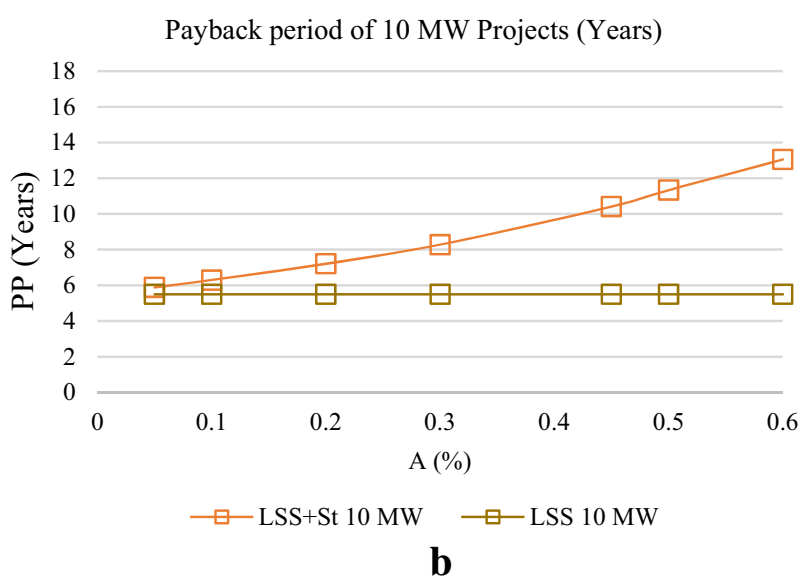

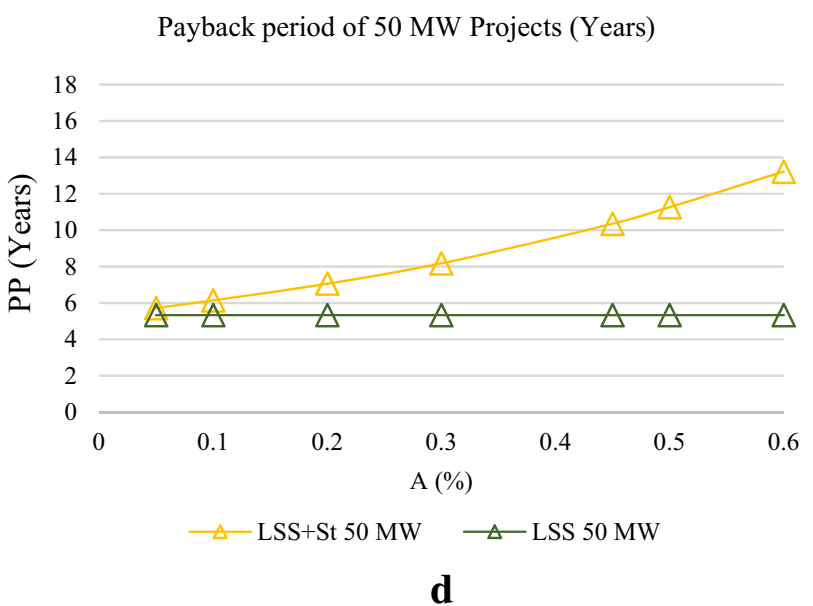

d

Fig. 10 Payback period of the different investment types for each LSS capacity. a 6-MW projects, b 10-MW projects, c 30-MW projects, d 50-MW projects

times longer than LSS projects. Since the NPW of storage projects is negative for all the investment cases, the values of $\mathrm{PP}$ of those projects are all negative, which is the reason for not presenting them in Figs. 9 and 10.

\section{Perak economic analysis Net present worth}

The NPW of the different investment cases in Perak is shown in Figs. 11 and 12.

In Perak, the NPW for the different investment types with variation of " $A$ " has the same pace as in Pahang. The difference is within the value of " $A$ ", above which the NPW of the LSS + St projects are negative. While it is $43 \%$ in Pahang, it is $47 \%$ in Perak. While the highest NPW for LSS + St project in Pahang is for $50 \mathrm{MW}$, equal to RM 123.74 million (USD 30 million), it is higher in Perak for the same investment case, with a value of RM 137 million (USD 33.2 million).
The NPW in Perak is higher than those in Pahang. For 6-MW projects, the difference in terms of NPW of LSS + St projects between Pahang and Perak is RM 0.07 to RM 0.09 million (USD 0.017 million to USD 0.022 million). For 10-MW projects, the difference is between RM 0.1 million (USD 0.0242 million) and RM 0.13 million (USD 0.0315 million). For $30-\mathrm{MW}$ projects, the difference is higher, ranging from RM 0.29 million (USD 0.0702 Million) to RM 0.67 million (USD 0.1624 million). The difference between the two locations is comparatively higher for $50-\mathrm{MW}$ projects. It is equal to RM 11.67 million (USD 2.83 million) for $A=60 \%$, while it is equal to RM 13.5 million (USD 3.27 million) with $A=5 \%$. The highest difference between Pahang and Perak is with LSS projects. It is equal to RM 13.65 million (USD 3.309 million) for 50-MW projects. The NPW of storage projects is nearly the same in Pahang and Perak for each LSS capacity. 


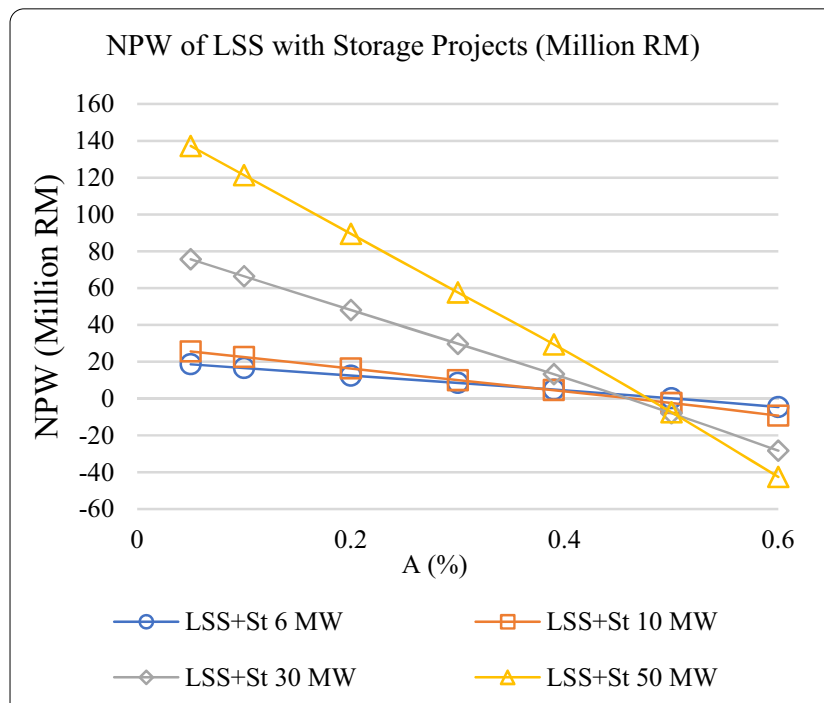

$\mathbf{a}$

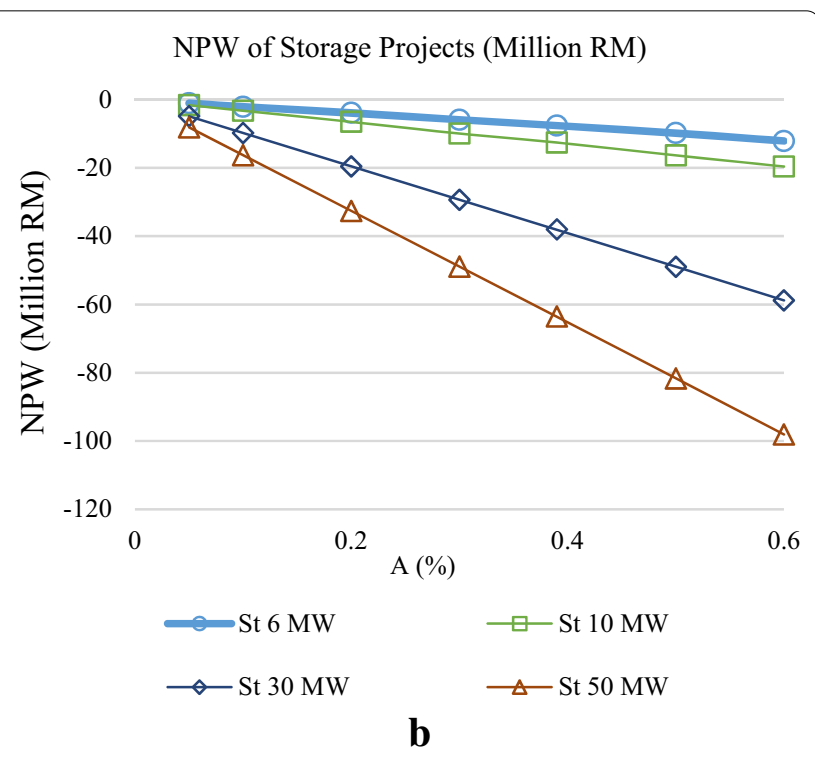

NPW of LSS Projects (Million RM)

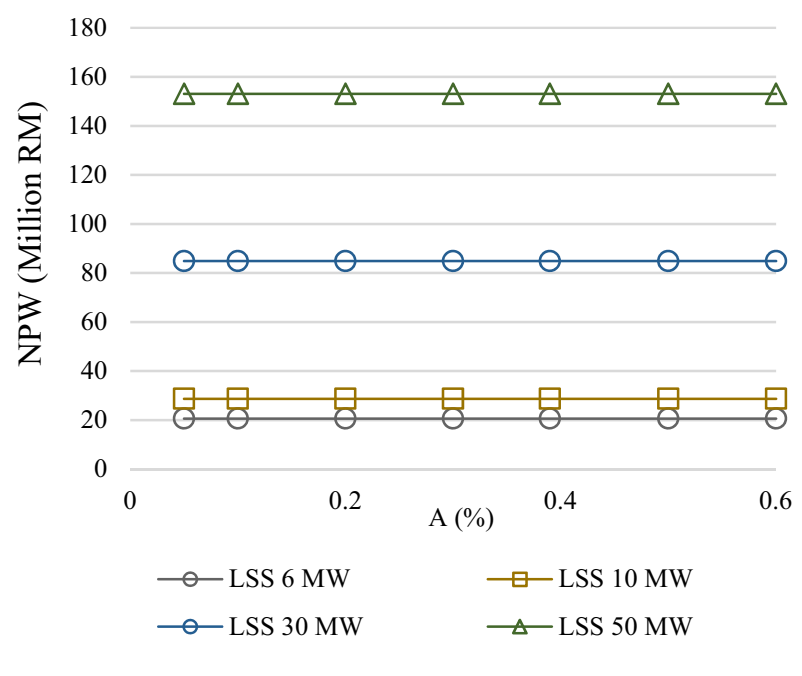

c

Fig. 11 Net present worth of different LSS capacities with variation of " $A$ " in Perak. a LSS with storage projects, b storage projects and c LSS projects

\section{Net present cost}

The net present costs of all the investment cases are the same in Pahang and Perak. This is due to the equal costs of the components in Peninsular Malaysia. The net present costs in Perak are presented in Fig. 13.

\section{Levelized cost of electricity}

The difference in terms of LCOE between Pahang in Perak is in the range of RM $0.001 / \mathrm{kWh}$. This is due to the equal NPC values and the same prices of selling electricity, used for both locations. The LCOE of the different investment cases in Perak is shown in Fig. 14.

\section{Payback period and reflective analysis for Malaysia context} The same as NPC and LCOE, the payback period of the different investment cases in Perak and Pahang are nearly equal. The PP periods of all the investment cases in Perak are shown in Fig. 15. Energy storage has become a viable technology to reduce the peak demand. Battery energy storage system (BESS) has been gaining more attention with the increase in electricity generation by renewable energy resources like solar PV. The support of BESS will be necessary at a certain point of penetration as the ventures into renewable energy in Malaysia continue to increase. Based on studies, as Malaysia targets reaching 


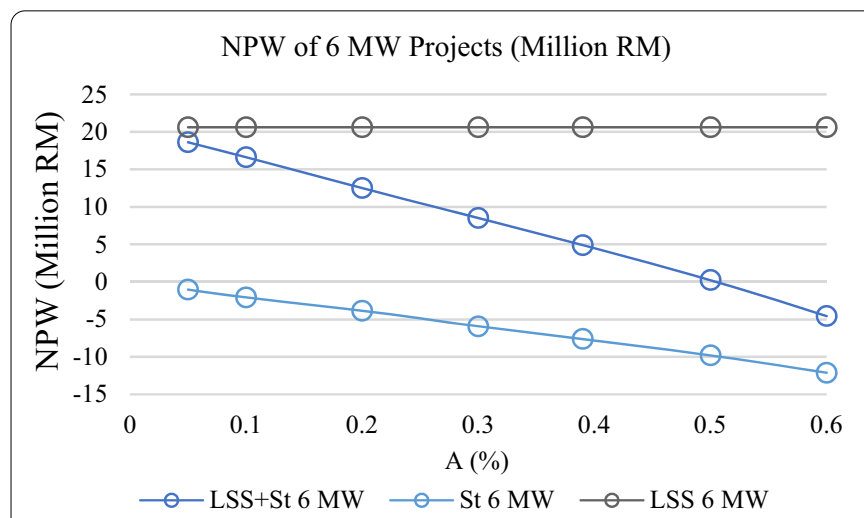

a

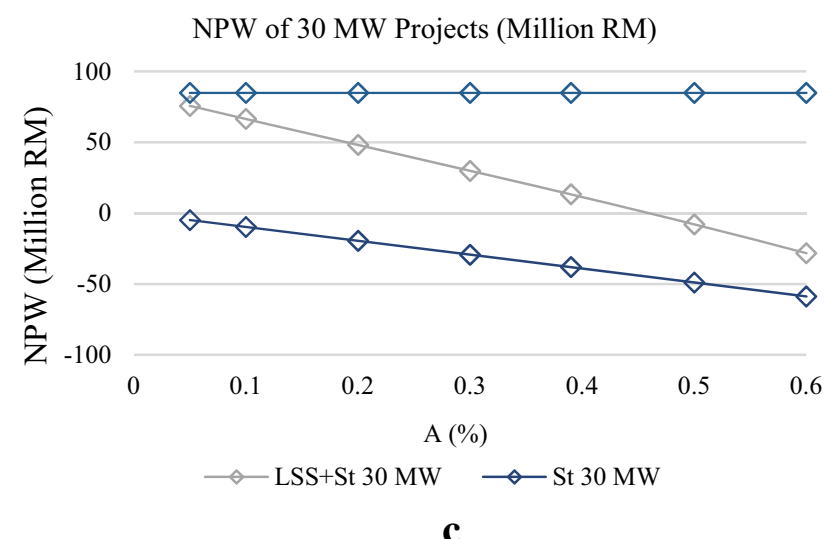

NPW of 10 MW Projects (Million RM)

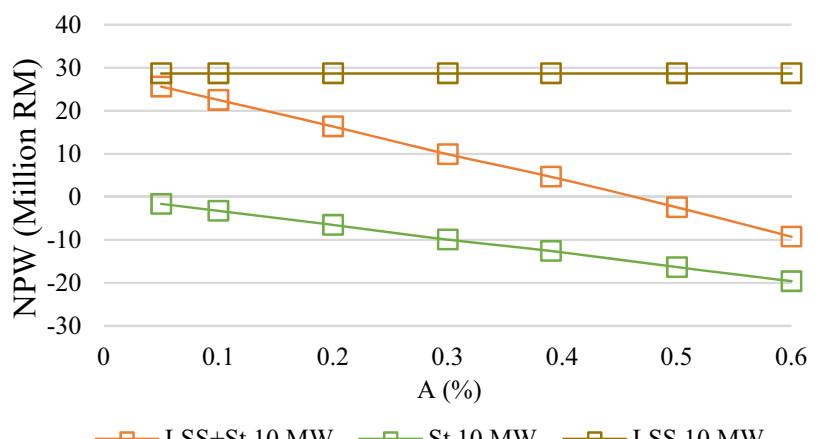

b

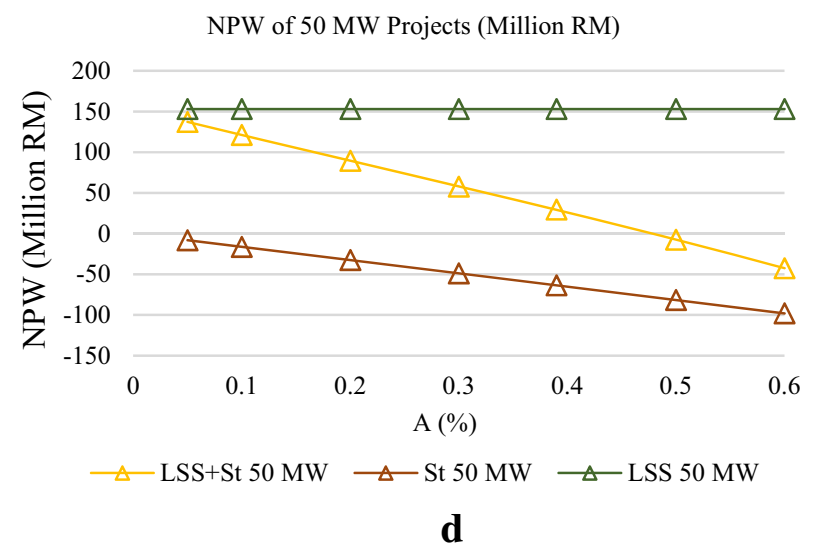

d

Fig. 12 Net present worth of the different investment types for each LSS capacity in Perak. a 6-MW projects, b 10-MW projects, c 30-MW projects, d 50-MW projects

$20 \%$ generation from RE, the support of BESS is necessary to realize this goal (Akinyele and Rayudu 2014; Lucas and Chondrogiannis 2016; McPherson and Tahseen 2018). In Malaysia, BESS for behind-the-meter (BTM) which is can be utilized as backup power, peak demand reduction, energy arbitrage and increased PV solar selfconsumption has become a research priority. However, large-scale batteries, there has not been recent deployment as the capital cost of these projects can be very expensive. With the lack of support from the government with proper incentives and regulations, the ventures into BESS can be a challenge. Based on past studies, the reduction of electricity prices when using lead-acid battery storage system to decrease the maximum demand is an economical viable option (Chua et al. 2015). The value of a lithium ion battery has been predicted to drop from $\$ 600 / \mathrm{kWh}$ to $\$ 200 / \mathrm{kWh}$ by the year 2020 . This price reduction will be a motivation to venture into energy storage as an option to negate the peak demand. A study conducted by Parra and Patel (2016), has proven that simple retail tariffs, where electricity prices are constant in a day is the best viable option for consumers that use PV-coupled battery systems that only perform PV energy time shift. Sustainable Energy Development Authority (SEDA) has been proactively executing advanced and robust incentives and policies to increase the ventures into renewable energy in Malaysia. To ensure Malaysia achieves its target of one third of renewable energy production by the year 2030, several optimizations must be carried out on the existing policies. The feed-in-tariff (FiT) system needs to be extended and this can be done by implementing a responsive digression model and to further improve the funding for FiT. Digression rates should be set to be evaluated in 2-year intervals for PV will allow real pricing information to drive the digression rates; this ensures that accurate data are used to influence these rates. The FiT is by a $1.6 \%$ tariff on consumer electrical consumption. Green energy bonds and carbon tax have been introduced to ensure renewable energy becomes a part of the Malaysia's energy mix. Carbon tax is expected to improve the funding of FiT. With the introduction of green energy bonds, investors will be assured 

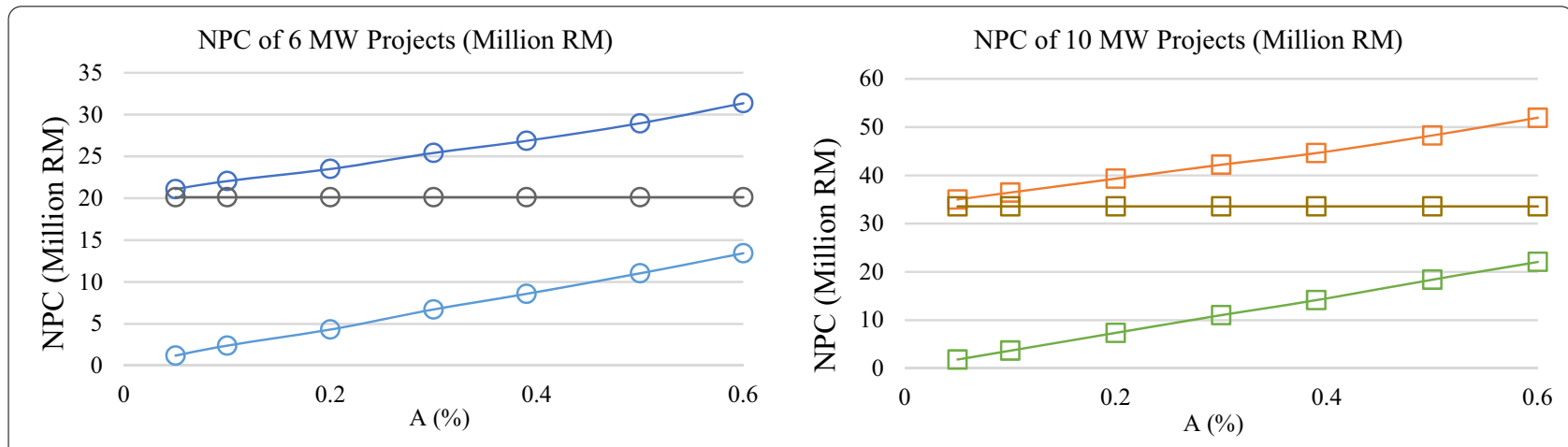

$\multimap$ LSS+St 6 MW $\multimap$ St 6 MW $\multimap$ LSS 6 MW

a

$\longrightarrow$ LSS+St $10 \mathrm{MW} \longrightarrow$ - St $10 \mathrm{MW} \longrightarrow$ - LSS $10 \mathrm{MW}$

b

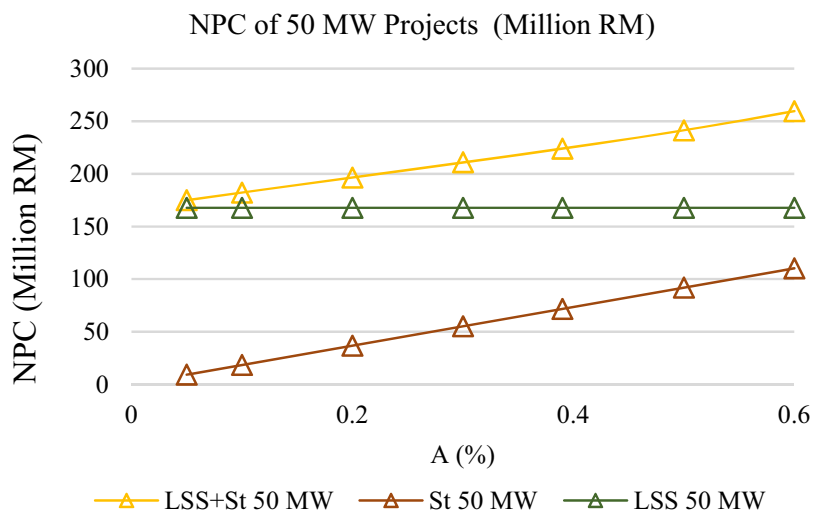

d

Fig. 13 Net present cost of the different investment types for each LSS capacity in Perak. a 6-MW projects, b 10-MW projects, c 30-MW projects, d 50-MW projects

that there will be a stable return of interest and reliable payback time.

\section{Conclusions}

The multiple investment cases examined in the economic analysis, aim to study the profitability of investing in LSS, in storage and in both together. It is clear after the simulations and the calculations done on different LSS capacities in Pahang and Perak, that storage as investment is not financially profitable. A policy implying incentives on the cost of electricity charging the storage is imperative to make such investment profitable. Furthermore, encouraging the manufacturing of energy storage technologies could have a positive impact on the storage projects costs, and consequently make the investment competitive and profitable. LSS with storage as one project is profitable in most of the cases, but as long as the storage output to LSS output ratio is smaller, the benefits are higher to the investor and the payback period is shorter. It can be seen at this point, that the aims of the authorities will not meet those of private investors. While the authorities will encourage and welcome more storage capacity, investors will be interested in lower storage capacities and even in LSS alone since it is more profitable. The lowest values of LCOE are guaranteed with energy storage output to LSS output ratio, $A=5 \%$. In this case, $30-\mathrm{MW}$ projects have the cheapest electricity, equal to RM $0.2484 / \mathrm{kWh}$. On the other hand, increasing the energy storage output to LSS output ratio, $A$ to $60 \%$ results in the increase of LCOE, exceeding RM $0.47 / \mathrm{kWh}$. Carrying out the economic analysis, in two states, Pahang and Perak, where the main difference is the GHI, showed that even with exactly the same costs for the same project scales, profitability of LSS with energy storage investments can be different. With a difference of only $0.06 \mathrm{kWh} / \mathrm{m}^{2} /$ day between Pahang and Perak, the difference in NPW is more than $7.5 \%$ of the NPC, which is equal for the same investment type and size in both locations. The difference between the two 


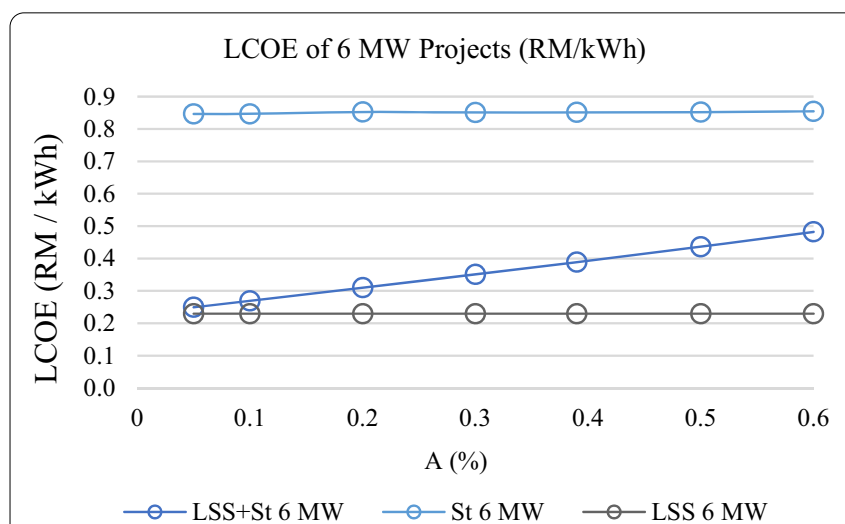

$\mathbf{a}$

LCOE of 30 MW Projects (RM/kWh)

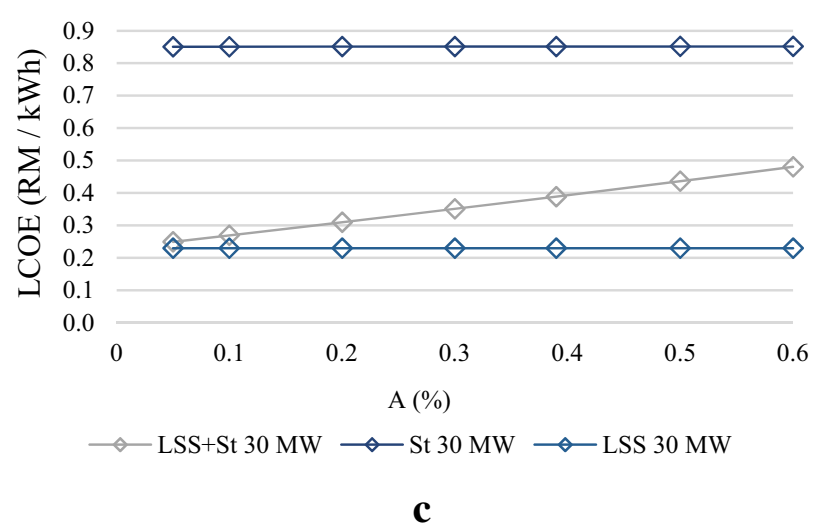

LCOE of 10 MW Projects (RM/kWh)

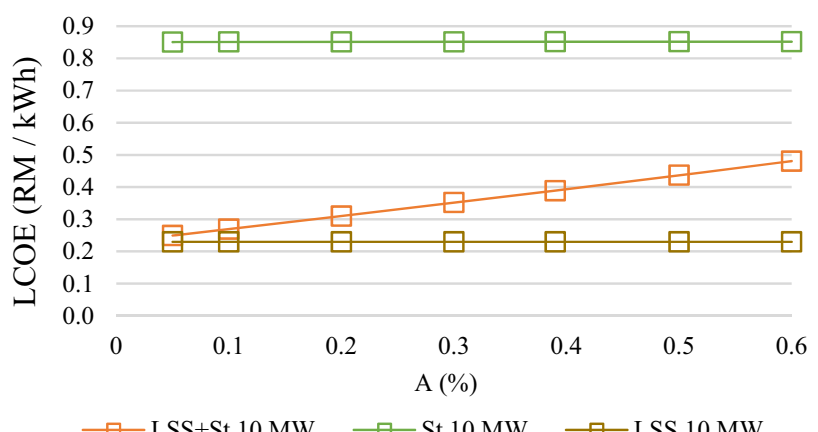

b

LCOE of $50 \mathrm{MW}$ Projects (RM/kWh)

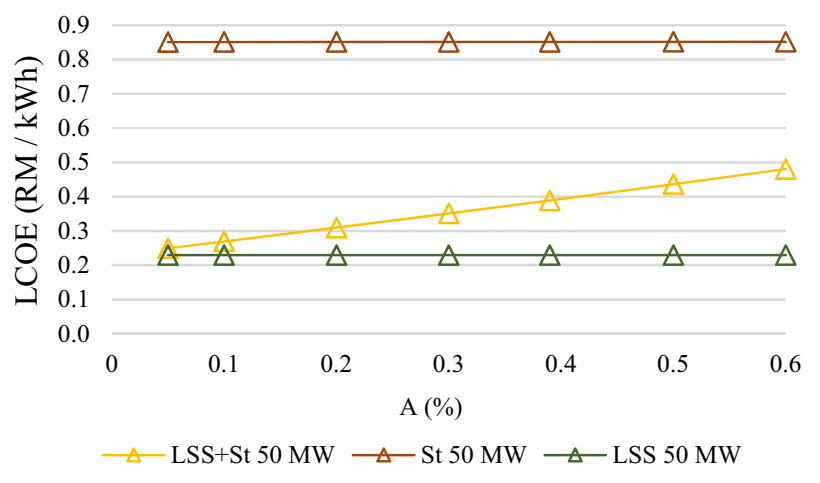

d

Fig. 14 Levelized cost of electricity of the different investment types for each LSS capacity in Perak. a 6-MW projects, b 10-MW projects, c 30-MW projects, d 50-MW projects

locations is comparatively higher for $50-\mathrm{MW}$ projects. It is equal to RM 11.67 Million for $A=60 \%$, while it is equal to RM 13.5 Million with $A=5 \%$.

\section{Recommendations and future work}

Incorporating a storage system in an LSS-PV will rectify the lack of energy to provide for the peak demand at night, and thus reduce the mismatch between the peak solar generation and the peak demand at night. This is a financially profitable and technically feasible option. The incorporation of storage system is beneficial to the environment as it reduces carbon dioxide emission and can ensure stable power generation. Flow batteries and lithium ion batteries are mature technologies that can provide the necessary capacity of storage to suffice for the peak demand at night. Ensuring a suitable energy management system, will promise constant feed of electricity generated by solar into the grid and charging of energy storage that will not cause any harm to the power system. The authorities may apply some new rules for investing in LSS, such as making a minimum storage capacity, a mandatory part of any LSS project. A low storage to LSS ratio can be used, allowing high profitability for investors, and guaranteeing the peak demand satisfaction by the totality of storage capacity in each state. It is recommended that the authorities may introduce regulations and rules when investing into LSS-PV, like the inclusion of a minimum storage capacity as a compulsory component in an LSS-PV project. In order to promise profitability for investors and stakeholders, a low storage to LSS-PV ratio can be used which also satisfies the night peak demand of each state. Further studies on the use of lead-acid batteries and lithium ion batteries can be of benefit for future projects. Studies of this nature allow a comprehensive understanding of power systems with similar installed capacities but with the usage of other storage technologies. Such studies will make it possible to compare 


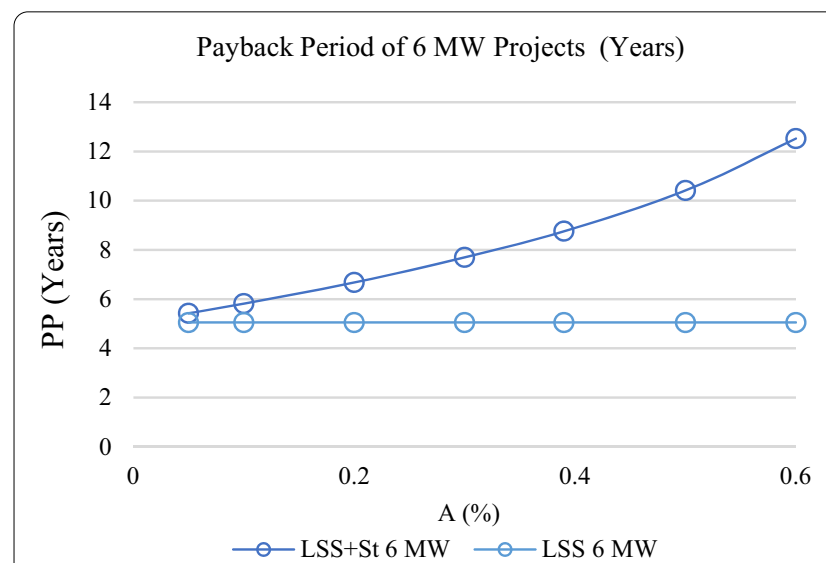

$\mathbf{a}$

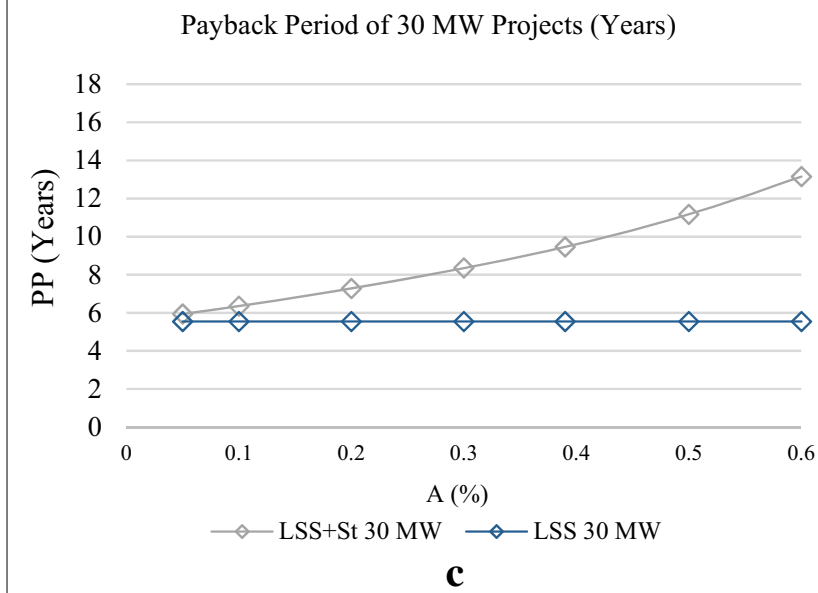

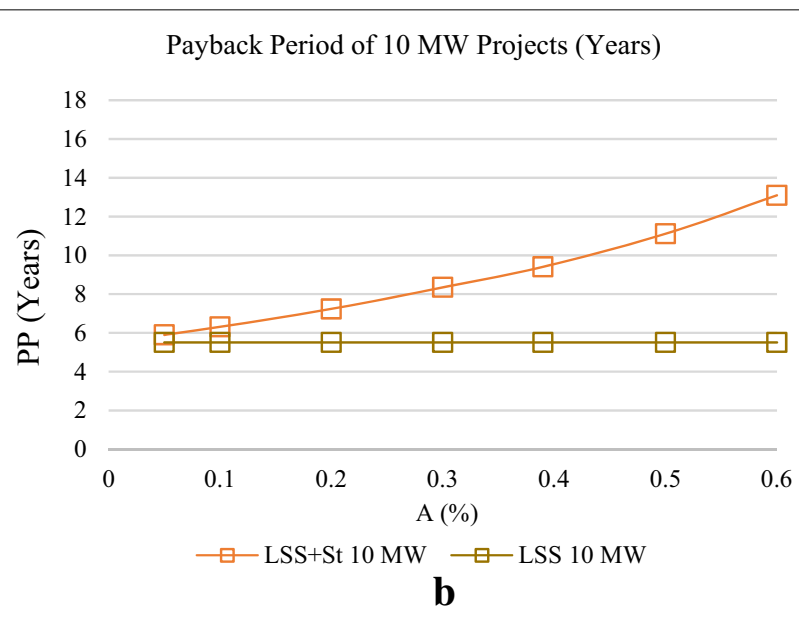

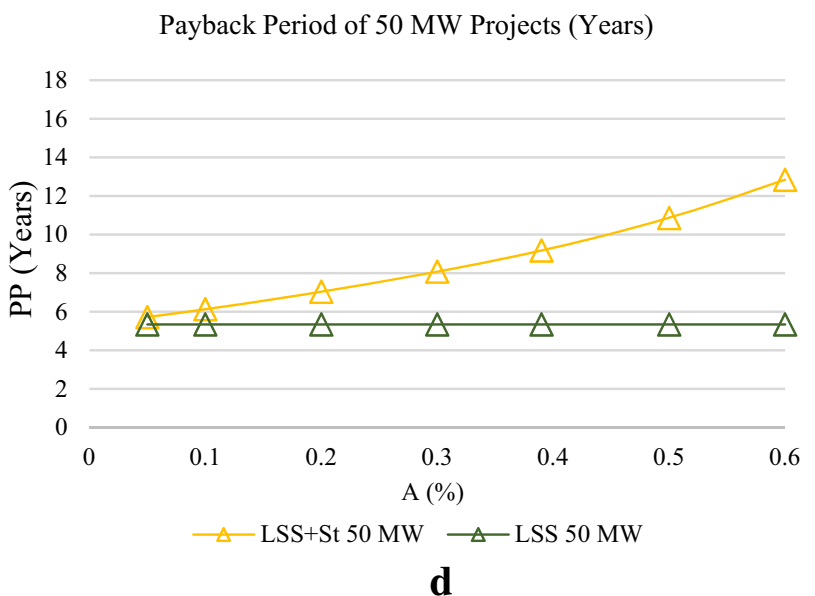

Fig. 15 Payback period of the different investment types for each LSS capacity in Perak. a 6-MW projects, b 10-MW projects, c 30-MW projects, d 50-MW projects

the profitability of power systems having the similar installed capacities but using different technologies. In order to ensure the environment benefits from this, the installed capacity of LSS-PV should be increased. The electricity consumption of the country should be maintained or reduced to avoid an increase in energy storage capacity that is evidently depended on the electricity load. Once these goals are achieved, the GHG emission of the country will reduce significantly.

\section{Supplementary Information}

The online version contains supplementary material available at https://doi. org/10.1186/s40807-020-00064-5.

Additional file 1. Cost analysis for various energy storage types, demand profiles, meteorological data for case study in Pahang state. Cost analysis for various energy storage types, demand profiles, meteorological data for case study in Perak state. Cost of components/balance of system (BOS).

\section{Abbreviations}

LSS: Large-scale solar; PV: Photovoltaic; LSS + ST: Projects of LSS combined with energy storage; ST: Projects including energy storage only; A: Energy storage output/LSS output; GHI: Global horizontal irradiation; FiT: Feed-in tariff; TNB: Tenaga National Berhad; RE: Renewable energy; BEES: Battery energy storage system; NPW: Net present worth; NPC: Net present cost; PP: Payback period; LCOE: Levelized cost of electricity; PPA: Power purchase agreement; CSV: Component salvage value; OECD: Organisation for Economic Co-operation and Development; ROI: Return of investment; BTM: Behind-the-meter.

\section{Acknowledgements}

This work was funded by the Energy Academy, Heriot-Watt University under the "Fledge Project". It is a part of the research "Large-Scale Solar Power: Solutions and Techno Social-Economic Implications to Malaysia in Meeting World Energy Challenges by 2030".

\section{Authors' contributions}

ML (first author), YIG (second author). Both authors read and approved the final manuscript.

\section{Funding}

Energy Academy, Fledge Funding. 


\section{Availability of data and materials}

The spatial data availability are the limiting factor in the application of cost estimations due to the calculation method mentioned by Sabo et al. (2019), relies heavily on the topography, road networks, different forms of electrical demands and demographic data as these data are owned and secured by utility providers and government.

\section{Ethics approval and consent to participate}

NA.

\section{Consent for publication}

NA.

\section{Competing interests}

The authors declare that they have no competing interests.

Received: 15 March 2020 Accepted: 12 December 2020

Published online: 22 January 2021

\section{References}

Akinyele, D., \& Rayudu, R. (2014). Review of energy storage technologies for sustainable power networks. Sustainable Energy Technologies and Assessments, 8, 74-91.

Azmana, N., Abdullah, M., Hassana, M., Saida, D., \& Hussin, F. (2017). Enhanced time of use electricity pricing for commercial customers in Malaysia. Pertanika Journal of Science and Technology, 25, 285-294.

Babacan, O., Ratnam, E. L., Disfani, V. R., \& Kleissl, J. (2017). Distributed energy storage system scheduling considering tariff structure, energy arbitrage and solar PV penetration. Applied Energy, 205, 1384-1393. https://doi. org/10.1016/j.apenergy.2017.08.025).

Bazilian, M., Onyeji, I., Liebreich, M., MacGill, I., Chase, J., Shah, J., Gielen, D., Arent, D., Landfear, D., \& Zhengrong, S. (2019). Re-considering the economics of photovoltaic power. [Online]. Available: https://doi. org/10.1016/j.renene.2012.11.029. Accessed: 12-May-2019.

Brankera, K., Pathak, M., \& Pearce, J. (2011). A review of solar photovoltaic levelized cost of electricity. Renewable and Sustainable Energy Reviews, 15(9) 4470-4482. https://doi.org/10.1016/j.rser.2011.07.104.

Che Mud, S. (2019). Head of terms for large scale solar PPA for MW connection. Energy Commission [Online]. Available: https://www.st.gov.my. Accessed 06 Sept 2018

Chua, K. H., Lim, Y. S., \& Morris, S. (2015). Cost-benefit assessment of energy storage for utility and customers: A case study in Malaysia. Energy Conversion and Management, 106, 1071-1081.

Electricity Statistics-Electricity Average Selling Price. (2019). Energy Commission—Suruhanjaya Tenaga [Online]. Available: https://meih.st.gov. my/statistics?p_auth=WBr6mLV4\&p_p_id=Eng_Statistic_WAR_STOAS PublicPortlet\&p_p_lifecycle $=1 \&$ p_p_state $=$ maximized\&p_p_ mode=view\&p_p_col_id=column-1\&p_p_col_pos=1\&p_p_col_coun =2\&_Eng_Statistic_WAR_STOASPublicPortlet_execution=e1s1\&_Eng_ Statistic_WAR_STOASPublicPortlet_eventld=ViewStatisticELC16\&categ oryld $=10 \&$ flowld $=125$. Accessed 14 Jan 2019.

Energy Commission. 2016a. Request for proposal (RFP) for the development of large scale solar photovoltaic (LSSPV) plants in Peninsular Malaysia and Sabah for commercial operation in 2017-2018-Announcement of shortlisted bidders. Putrajaya, Malaysia.

Energy Commission. 2016b. Submission of bids_Large scale solar photovoltaic plant (LSS) for 2017/2018. Putrajaya, Malaysia.

Energy Commission. 2017a. Request for proposal (RFP) for the development of large scale solar photovoltaic (LSSPV) plants in Peninsular Malaysia, Sabah and Labuan for commercial operation in 2019-2020-Announcement of Shortlisted bidders. Putrajaya, Malaysia.

Energy Commission. 2017b. Submission of bids_Large scale solar photovoltaic plant (LSS) for 2019/2020. Putrajaya, Malaysia.

EL-Shimy, M. (2009). Viability analysis of PV power plants in Egypt. Renewable Energy, 34(10), 2187-2196. https://doi.org/10.1016/j.renene.2009.01.010
Harder, E., \& Gibson, J. (2011). The costs and benefits of large-scale solar photovoltaic power production in Abu Dhabi, United Arab Emirates. Renewable Energy, 36(2), 789-796. https://doi.org/10.1016/j.renene.2010.08.006.

Hussain, A.., Mezher, T., \& Griffiths, S. (2013). Economic assessment of large scale solar photovoltaic projects in the UAE. In 2013 International Conference on Engineering, Technology and Innovation (ICE) and IEEE International Technology Management Conference [Online]. Available: https:// doi.org/10.1109/ITMC.2013.7352665. Accessed: 01-May-2019.

International Renewable energy agency. (2017). Electricity storage and renewables: Costs and markets to 2030". Abu Dhabi, p. 19, 50-54, 63-81, $82-86,87,90$

Investopedia. (2019). How payback periods work. [online] Available at: https ://www.investopedia.com/terms/p/paybackperiod.asp. Accessed 5 May 2019

Laajimi, M., \& Go, Y. I. (2019). Energy storage system design for large-scale solar PV in Malaysia: technicaland environmental assessments. Journal of Energy Storage, 26, 100984. https://doi.org/10.1016/j.est.2019.100984.

Lai, C. \& McCulloch, M. (2019). Levelized cost of electricity for solar photovoltaic and electrical energy storage. Applied Energy. https://doi. org/10.1016/j.apenergy.2016.12.153.

Lucas, A., \& Chondrogiannis, S. (2016). Smart grid energy storage controller for frequency regulation and peak shaving, using a vanadium redox flow battery. International Journal of Electrical Power and Energy Systems, 80, 26-36.

Malaysia Inflation Rate-Forecast. (2018). Tradingeconomics.com [Online]. Available: https://tradingeconomics.com/malaysia/inflation-cpi/forecast. Accessed 23 May 2018.

McPherson, M., \&Tahseen, S. (2018). Deploying storage assets to facilitate variable renewable energy integration: The impacts of grid flexibility, renewable penetration, and market structure. Energy, 145, 856-870.

Mohammadi, K., Naderi, M., \& Saghafifar, M. (2018). Economic feasibility of developing grid-connected photovoltaic plants in the southern coast of Iran. Energy, 156, 17-31. https://doi.org/10.1016/j.energy.2018.05.065.

Net Present Value (NPV). (2019). Investopedia [Online]. Available: https://www. investopedia.com/terms/n/npv.asp. Accessed 06 May 2019

Overview of the FiT System in Malaysia. (2018). Seda.gov.my [Online]. Available: http://seda.gov.my/overview_of_fit_concept_in_malaysia.html Accessed 24 June 2018

Parra, D., \& Patel, M. K. (2016). Effect of tariffs on the performance and economic benefits of PV-coupled battery systems. Applied Energy, 164 175-187.

Pawel, I. (2014). The cost of storage-How to calculate the levelized cost of stored energy (LCOE) and applications to renewable energy generation. Energy Procedia, 46, 68-77.

Pillai, G., \& Naser, H. (2018). Techno-economic potential of large-scale photovoltaics in Bahrain. Sustainable Energy Technologies and Assessments, 27, 40-45. https://doi.org/10.1016/j.seta.2018.03.003.

Poullikkas, A. (2013). A comparative overview of large-scale battery systems for electricity storage [online]. http://www.elsevier.com/. Available at: https ://doi.org/10.1016/j.rser.2013.07.017. Accessed 13 Mar 2018.

PV Derating Factor. (2018). Homerenergy.com [Online]. Available: https://www. homerenergy.com/products/pro/docs/3.11/pv_derating_factor.html. Accessed 17 June 2018.

Ramadhan, M., \& Naseeb, A. (2011). The cost benefit analysis of implementing photovoltaic solar system in the state of Kuwait. Renewable Energy, 36(4), 1272-1276. https://doi.org/10.1016/j.renene.2010.10.004

Renewables. (2016). Global status report. Available online: http://www.ren21 .net/wp-content/uploads/2016/05/GSR_2016_Full_Report_lowres.pdf. Accessed on 02 June 2018.

Return on Investment (ROI). (2019). Investopedia [Online]. Available: https:// www.investopedia.com/terms/r/returnoninvestment.asp. Accessed 10 May 2019.

Sabo, M., Mariun, N., Hizam, H., Mohd Radzi, M., \& Zakaria, A. (2019). Spatial matching of large-scale grid-connected photovoltaic power generation with utility demand in Peninsular Malaysia. Applied Energy. https://doi. org/10.1016/j.apenergy.2017.01.087.

Salvage Value. (2018). Homerenergy.com [Online]. Available: https://www. homerenergy.com/products/pro/docs/3.11/salvage_value.html. Accessed 02 July 2018. 
SEDA. (2016). National survey report of PV power applications in Malaysia 2016. Putrajaya, Malaysia.

Silvi, C. (2008). History and future of renewable solar energy. Development, 51, 409-414. https://doi.org/10.1057/dev.2008.45.

Singh, S., Singh, M., \& Kaushik, S. C. (2016). Feasibility study of an islanded microgrid in rural area consisting of $\mathrm{PV}$, wind, biomass and battery energy storage system. Energy Conversion and Management, 128, 178-190. https ://doi.org/10.1016/j.enconman.2016.09.046.

Solar panel efficiency | Solar System Malaysia. (2012). Solarsystemmalaysia.com [Online]. Available: http://www.solarsystemmalaysia.com/tag/solar-panel -efficiency/. Accessed: 09 June 2018.

TNB ENHANCED TIME OF USE (ETOU). (2018). Tenaga National Berhad [Online]. Available: https://www.tnb.com.my/faq/etou/. Accessed 24 May 2018.
XE: Convert MYR/USD. (2019). Malaysia Ringgit to United States Dollar, Xe.com [Online]. Available: https://www.xe.com/currencyconverter/conve $\mathrm{rt} /$ ?Amount=1\&From=MYR\&To=USD. Accessed 26 Jan 2019.

Ye, J., Reindl, T., Aberle, A., \& Walsh, T. (2014). Performance degradation of various PV module technologies in tropical Singapore. IEEE Journal of Photovoltaics, 4(5), 1288-1294.

Zou, H., Du, H., Brown, M., \& Mao, G. (2017). Large-scale PV power generation in China: A grid parity and techno-economic analysis. Energy, 134, 256-268. https://doi.org/10.1016/j.energy.2017.05.192.

\section{Publisher's Note}

Springer Nature remains neutral with regard to jurisdictional claims in published maps and institutional affiliations.

\section{Submit your manuscript to a SpringerOpen ${ }^{\circ}$ journal and benefit from:}

- Convenient online submission

- Rigorous peer review

- Open access: articles freely available online

- High visibility within the field

- Retaining the copyright to your article

Submit your next manuscript at springeropen.com 